\title{
Comparative Study of Time-Frequency Decomposition Techniques for Fault Detection in Induction Motors Using Vibration Analysis during Startup Transient
}

\author{
Paulo Antonio Delgado-Arredondo, ${ }^{1}$ Arturo Garcia-Perez, ${ }^{1}$ \\ Daniel Morinigo-Sotelo, ${ }^{2}$ Roque Alfredo Osornio-Rios, ${ }^{3}$ Juan Gabriel Avina-Cervantes, ${ }^{1}$ \\ Horacio Rostro-Gonzalez, ${ }^{1}$ and Rene de Jesus Romero-Troncoso ${ }^{1}$ \\ ${ }^{1}$ HSPdigital-CA Telematica, Procesamiento Digital de Señales, DICIS, Universidad de Guanajuato, \\ Carretera Salamanca-Valle km 3.5+1.8, Palo Blanco, 36700 Salamanca, GTO, Mexico \\ ${ }^{2}$ Department of Electrical Engineering, University of Valladolid (UVa), 47011 Valladolid, Spain \\ ${ }^{3}$ HSPdigital-CA Mecatronica, Facultad de Ingenieria, Universidad Autonoma de Queretaro, Campus San Juan del Rio, \\ Rio Moctezuma 249, 76807 San Juan del Río, QRO, Mexico
}

Correspondence should be addressed to Rene de Jesus Romero-Troncoso; troncoso@hspdigital.org

Received 15 April 2015; Revised 4 June 2015; Accepted 8 June 2015

Academic Editor: Francesco Franco

Copyright (C) 2015 Paulo Antonio Delgado-Arredondo et al. This is an open access article distributed under the Creative Commons Attribution License, which permits unrestricted use, distribution, and reproduction in any medium, provided the original work is properly cited.

Induction motors are critical components for most industries and the condition monitoring has become necessary to detect faults. There are several techniques for fault diagnosis of induction motors and analyzing the startup transient vibration signals is not as widely used as other techniques like motor current signature analysis. Vibration analysis gives a fault diagnosis focused on the location of spectral components associated with faults. Therefore, this paper presents a comparative study of different timefrequency analysis methodologies that can be used for detecting faults in induction motors analyzing vibration signals during the startup transient. The studied methodologies are the time-frequency distribution of Gabor (TFDG), the time-frequency Morlet scalogram (TFMS), multiple signal classification (MUSIC), and fast Fourier transform (FFT). The analyzed vibration signals are one broken rotor bar, two broken bars, unbalance, and bearing defects. The obtained results have shown the feasibility of detecting faults in induction motors using the time-frequency spectral analysis applied to vibration signals, and the proposed methodology is applicable when it does not have current signals and only has vibration signals. Also, the methodology has applications in motors that are not fed directly to the supply line, in such cases the analysis of current signals is not recommended due to poor current signal quality.

\section{Introduction}

Induction motors are one of the most used machines in the world. The applications are varied and the advantages of their use are numerous. About half of the electricity consumed by the industry in the U.S. is used by induction motors; in fact, $89 \%$ of the engines in manufacturing are electric motors [1]. They are also present in various modes of transportation. As a result, they are basic elements in the modern industrial world. From this arises the need for quick and accurate fault diagnosis for anticipating work stoppage in the processes where these machines are used. Failures in induction motors can occur in any of their three major components: rotor, stator, and bearings [2]. Actually, 38\% of failures occur in the stator, $10 \%$ are located in the rotor, and around $40 \%$ represent mechanical failures including bearing damage, misalignment, eccentricity, and shaft bending [3].

The most popular techniques for fault detection in induction motors are the motor current signature analysis (MCSA) and the vibration analysis. MCSA allows noninvasive fault 
diagnosis online [4]. This technique uses a Hall-effect sensor to measure signals of stator current and a data acquisition system to acquire the signal [5]. This current signal is then analyzed to determine the signature and characteristic features of components associated with different faults, which can be magnified during the startup transient because the motor operates in stressed conditions [6]. Vibration analysis techniques, on the other hand, are used to make the diagnosis of faults in induction motors using vibration signals from three spatial axes [7]; this technique is particularly suited for determining mechanical faults. The measurement of vibrations is made using accelerometers as primary sensors. The vibration signals are then registered with the data acquisition system [5]. Vibrations in an induction motor are affected by variations in the magnetomotive forces caused by faults in the machine or faults that cause abnormal motor rotation. This technique is noninvasive and does a very feasible job at finding the location of faults [8]. These two techniques can be used both during the startup transient and steady-state operating regimes. Depending on which operating regime is used for monitoring the motor condition, there are certain characteristics associated with different fault conditions.

The set of techniques for fault diagnosis of induction motors, by analyzing the startup transient vibration signals, is not as widely used compared with those that analyze current signals. Vibration analysis and MCSA give a fault diagnosis focused on the location of spectral components associated with faults, using the Fourier transform which translates a signal from the time domain to the frequency domain, displaying the entire frequency content of a signal, but does not allow observing of the evolution of the signal frequency content over time. This is the reason for extending the Fourier transform capabilities such as linear time-frequency decompositions (short-time Fourier transform and wavelet transform), quadratic time-frequency decompositions, and distributions of time-frequency energy, which allow the evolution of frequency content throughout the duration of the signal in time. This is very useful for nonstationary signals, such as those obtained from the motor startup transient, because signatures associated with faults evolve over time and their frequency content does not remain constant but varies along the startup transient. To locate the signatures associated with motor faults, different tools have been used on MCSA for time-frequency decomposition, allowing tracing of the evolution of such frequencies in time. Examples of these decompositions are the short-time Fourier transform [912], discrete wavelet transform [12-15], continuous wavelet transform [16-19], the Hilbert transform [20, 21], the HilbertHuang Transform [20, 21], the Wigner-Ville distribution [2227], the Choi-Williams distribution [26-28], and multiple signal classification (MUSIC) [5]. Some of these tools work together with artificial intelligence classifiers for decisionmaking about the components or signatures that are present in the signals for identifying faults and their severity, such as artificial neural networks (ANN), fuzzy logic, fuzzy neural networks, and genetic algorithms [6, 10, 14, 16, 17, 24, 29]. Garcia-Perez et al. [5] presented a study for the detection of multiple faults in an induction motor by applying MUSIC to a current signal during the steady-state regime. Afterwards, Garcia-Perez et al. [30] extended the fault detection method of multiple faults in an induction motor with MUSIC including sound signals along with vibration signals, also during the steady-state regime. Rodriguez-Donate et al. [31] developed a method for the identification of multiple faults in an induction motor directly fed to the power grid, based on the discrete wavelet transform (DWT) applied to the startup vibration transient. Pilloni et al. [19] presented a comparative study of different methodologies including the fast Fourier transform (FFT), Hilbert transform (HT), DWT, continuous wavelet transform (CWT), and the Wigner-Ville distribution (WVD) applied to the stator current signal in induction motors for fault detection in both steady-state and transient regimes. Garcia-Perez et al. [32] presented an experimental study of the time-frequency evolution characteristics during the startup transient of the current signal in an induction motor with a partially broken rotor bar when fed directly to the power grid applying MUSIC. Most of these techniques have been used to analyze stator current signals. In the case of vibration signals, there is not much research done to apply time-frequency decomposition techniques for analysis, where mostly the FFT [33] and the Zhao-Atlas-Marks (ZAM) distribution [34] for time-frequency decomposition have been used. Consequently, there is a need to investigate the suitability of time-frequency decomposition techniques to identify motor faults during the startup transient using vibration signals, applying a high-resolution spectral analysis as the MUSIC method.

The contribution of this work is a comparative study of different time-frequency analysis methodologies that can be used for detecting faults in induction motors analyzing vibration signals during the startup transient. The proposed methodologies are the time-frequency distribution of Gabor (TFDG), the time-frequency Morlet scalogram (TFMS), MUSIC, and FFT. The choice of TFDG and TFMS is based on their ability to reduce interferences, also known as crossterms between parallel evolving harmonics. MUSIC is the technique used in MCSA that has provided the best results, due to its very good frequency resolution. FFT is used as reference for comparison purposes with the other methodologies. The analyzed vibration signals in this paper are associated with the following motor faults: one broken rotor bar, two broken bars, unbalance, and bearing defects.

\section{Description of the Treated Faults}

Three common faults in induction motors are treated in this paper: unbalance condition (UNB), bearing faults (BDF), and broken rotor bars (BRB).

2.1. Unbalance (UNB). Mechanical balance in an induction motor involves the entire rotor structure which is made up of a multitude of parts including shaft, rotor laminations, end heads, rotor bars, end connectors, retaining rings, and fans. These many items must be designed and manufactured for an end assembly that achieves stable precision balance. When a motor is properly balanced and aligned, the frequency amplitude associated with the unbalance fault barely 
changes and remains bounded to a certain level. However, a mechanical unbalance in the induction motor involves a small radial vibration of the stator structure. The vibration level takes its maximum when the rotational speed equals the system natural frequency defined by $\omega_{0}=\sqrt{k / m}$, where $k$ is the stiffness factor and $m$ is the unbalance mass $[35,36]$. In addition, this vibratory signal oscillates at the rotational frequency, the vibration level is increased as well as the amplitude of the rotation frequency, and the same happens with its harmonics [37]. The analysis of vibration signals can provide a quick and easy way to extract information that permits the diagnosis about the presence of unbalance in an induction motor. The rated speed of the motor, normally expressed in revolutions per minute, is provided by the manufacturer. In asynchronous motors, this speed is slightly below the synchronous speed, $n_{s}$, that is related to the electrical supply frequency $f_{s}$ as follows:

$$
n_{s}=\frac{120 f_{s}}{P}
$$

where $P$ is the number of poles of the motor and the constant " 120 " is used to express the motor synchronous speed $n_{s}$ in revolutions-per-minute units.

2.2. Bearing Faults (BDF). Some authors [38] give a review of the causes and expected frequencies of vibration due to rolling element bearings. A variety of frequencies associated with the rotation of the motor can be calculated from the geometry of the bearing, such as the inner and outer race elements pass frequencies, the frequency of rotation for the cage, and rolling element spin frequency. A defect on the outer race causes an impulse each time rolling elements contact the defect. The rotor speed $\left(f_{r}\right)$ is the frequency at which the inner raceway rotates, which must be the frequency of the shaft. The physical phenomenon of the vibration generated in rolling elements such as bearings under the healthy condition can be explained as a combination of different sources such as modulation due to nonuniform loading, flexural bearing modes, and machinery-induced vibrations and noise. The bearing load is assumed to be an unbalanced force. Therefore, the radial load moves around the circumference of the outer ring as the shaft rotates. The single radial load transforms to a distributed load because the inner ring is in contact with more than one ball during the rotation. However, for the bearing fault condition when a defect in one surface of a bearing strikes a mating surface, an impulse is produced which excites resonances in the system. At time $t=0$, the defect is in contact with one of the rolling elements and lies at the center of the load zone on the line of action of the applied radial load. The mechanical system is symmetrical about the line of the applied load. As the bearing rotates, impacts occur at the ball-pass outer raceway frequency $\left(f_{\mathrm{BPOF}}\right)$ given by [39]

$$
f_{\mathrm{BPOF}}=\frac{N_{B}}{2} f_{r}\left(1-\frac{D_{B}}{D_{\mathrm{C}}} \cos \theta\right),
$$

where $\theta$ is the contact angle between the bearing surfaces, $D_{C}$ is the cage diameter of the bearing and is measured from a ball center to the opposite ball center, $D_{B}$ is the ball diameter, and $N_{B}$ is the number of balls in the bearing.

2.3. Broken Rotor Bars (BRB). In the case of rotor bars, it is known that symmetrical currents in a symmetrical rotor of an induction motor induce a resultant forward rotating magnetic field at synchronous speed with healthy rotor bars. The broken rotor bars result in rotor asymmetries; then there results a backward rotating field at slip frequency $s f_{s}$ with respect to the rotor. Interactions of the rotor backward rotating field with the stator field induce oscillating torque and oscillating velocity, and the frequency of this oscillation is $2 s f_{s}$, where this oscillation acts as a frequency modulation on the rotation frequency and a fault frequency $\left(f_{B B}\right)$ appears around $f_{r}$ in the vibration spectrum [40]:

$$
f_{B B}=k f_{r}-2 n s f_{s},
$$

where $f_{s}$ is the supply frequency, $s$ is the per-unit motor slip, $f_{r}$ is the rotor speed, and $k$ and $n$ are positive integers. The slip $s$ is defined as the relative mechanical speed of the motor $n_{m}$ with respect to the motor synchronous speed $n_{s}$ as follows:

$$
s=\frac{n_{s}-n_{m}}{n_{s}}
$$

\section{Theoretical Background}

3.1. Music Algorithm. The subspace methods are known as high-resolution methods that detect frequencies with low signal-to-noise ratio. The subspace methods assume that the discrete-time signal $x[n]$ can be represented by $m$ complex sinusoids in noise $e[n][5]$ as

$$
x[n]=\sum_{i=1}^{m} \bar{B}_{i} e^{j 2 \pi f_{i} n}+e[n], \quad n=0,1,2, \ldots, N-1
$$

with

$$
\overline{B_{i}}=\left|B_{i}\right| e^{\phi_{i}}
$$

where $N$ is the number of sample data, $B_{i}$ is the complex amplitude of the $i$ th complex sinusoid, $f_{i}$ is its frequency, and $e[n]$ is a sequence of white noise with zero mean and a variance $\sigma^{2}$. This method uses the eigenvector decomposition of $x[n]$ to obtain two orthogonal subspaces. The autocorrelation matrix $\mathbf{R}$ of the noisy signal $x[n]$ is the sum of signal and noise autocorrelation matrices $\left(\mathbf{R}_{s}\right.$ and $\mathbf{R}_{n}$, resp.):

$$
\mathbf{R}=\mathbf{R}_{s}+\mathbf{R}_{n}=\sum_{i=1}^{P}\left|B_{i}\right|^{2} e\left(f_{i}\right) e^{H}\left(f_{i}\right)+\sigma_{n}^{2} \mathbf{I},
$$

where $P$ is the number of frequencies and the exponent $H$ denotes the Hermitian transpose. I is the identity matrix, and $e^{H}\left(f_{i}\right)$ is the signal vector given by

$$
e^{H}\left(f_{i}\right)=\left[\begin{array}{llll}
1 & e^{-j 2 \pi f_{i}} & \cdots & e^{-j 2 \pi f_{i}(N-1)}
\end{array}\right] .
$$


From the orthogonality condition of both subspaces, the MUSIC pseudospectrum $Q$ is given by

$$
Q^{\text {MUSIC }}(f)=\frac{1}{\left|\mathbf{e}(f)^{H} \mathbf{V}_{m+1}\right|^{2}},
$$

where $\mathbf{V}_{m+1}$ is the noise eigenvector. This expression exhibits the peaks that are exactly at frequencies of principal sinusoidal components, where $\mathbf{e}(f)^{H} \mathbf{V}_{m+1}=0$.

3.2. Time-Frequency Distribution of Gabor. An extended version of the STFT (short-time Fourier transform) is the time-frequency distribution of Gabor (TFDG), which uses a Gaussian window type and a FT (Fourier transform) to achieve the time-frequency analysis [41]. The TFDG has a tradeoff drawback as the STFT, caused by the fixed width of the window, but it has better resolution in frequency than the STFT.

The TFDG is described by the following equation:

$$
G_{x}(t, f)=\int_{-\infty}^{\infty} e^{-\pi(\tau-t)^{2}} e^{-j 2 \pi f \tau} x(\tau) d \tau .
$$

As in the continuous case, the discrete TFDG is identical to discrete STFT, with the particular characteristic of the Gaussian window. The discrete TFDG can expand as a linear combination of Gabor coefficients and basic functions [42, $43]$. For a finite set of data $x[n]$, the Gabor expansion is obtained from

$$
x[n]=\sum_{m=0}^{M} \sum_{k=0}^{N} a_{m, k} g(n-m N) e^{j 2 \pi k n / k},
$$

where the array $a_{m, k}$ is periodic in $k$ and with period $K$. The sequence $g(n)$ is known as the synthesis window. The array of Gabor coefficients $a_{m, k}$ can be found via the TFDG:

$$
a_{m, k}=\sum_{n=0}^{N-1} x[n] w^{*}(n-m N) e^{-j 2 \pi k n / K}
$$

where the sequence $w(n)$ is the analysis window. The Zak transform is used to obtain the Gabor coefficients. The discrete Zak transform of a periodized window is defined as one-dimensional discrete Fourier transform of the sequence $W(n+m N)$ :

$$
Z=\sum_{m=0}^{N-1} W(n-m N) e^{-j 2 \pi m n(l / M N)},
$$

where $n$ and $l$ are adjustment parameters, $M$ is the period, and $N$ is the sample length.

3.3. Morlet Scalogram. Since the continuous wavelet transform behaves like an orthonormal basis decomposition, it can be shown that it preserves energy:

$$
\iint_{-\infty}^{\infty}\left|T_{x}(t, a ; \Psi)\right|^{2} d t \frac{d a}{a^{2}}=E_{x}
$$

where $E_{x}$ is the energy of $x$. This leads us to define the scalogram of $x$ as the squared modulus of the continuous wavelet transform. It is an energy distribution of the signal in the time-scale plane, associated with the measure $d t\left(d a / a^{2}\right)$.

As for the wavelet transform, time and frequency resolutions of the scalogram are related via the HeisenbergGabor principle: time and frequency resolutions depend on the considered frequency [44].

The frequency resolution is clearly a function of the frequency as it increases with $\omega$. The interference terms of the scalogram are restricted to those regions of the timefrequency plane where the corresponding autoscalograms (signal terms) overlap. Hence, if two signal components are sufficiently far apart in the time-frequency plane, their crossscalogram is essentially zero.

The Morlet wavelet is the most popular complex wavelet used in practice, whose mother wavelet is defined as

$$
\psi(t)=\frac{1}{\sqrt[4]{\pi}}\left(e^{j \omega_{0} t}-e^{-\omega_{0}^{2} / 2}\right) e^{-t^{2} / 2},
$$

where $\omega_{0}$ is the central frequency of the mother wavelet. Note that the term $e^{-\omega_{0}^{2} / 2}$ is used for correcting the nonzero mean of the complex sinusoid, and it can be negligible when $\omega_{0}>5$. Therefore, in some research the mother wavelet definition of the Morlet wavelet is given by

$$
\psi(t)=\frac{1}{\sqrt[4]{\pi}} e^{j \omega_{0} t} e^{-t^{2} / 2}
$$

where the central frequency $\omega_{0}>5$. The Morlet wavelet has a form very similar to the Gabor transform. The important difference is that the window function is also scaled by the scaling parameter, while the size of window in Gabor transform is fixed [45].

\section{Validation of the Proposed Techniques}

To validate the proposed methodology a synthetic signal is generated as stated in (17) with the aim to emulate some vibration harmonics, present in real signals of an electric motor. The synthetic signal has three pure sinusoidal signals with constant frequency at 80,670 , and $700 \mathrm{~Hz}$, plus a sinusoidal signal with variable frequency ranging from $0 \mathrm{~Hz}$ to $56.7 \mathrm{~Hz}$ from 0 to $2 \mathrm{~s}$ and then remaining with constant frequency. Normally distributed random noise is also added to the signal. The constant frequency components located at 670 and $700 \mathrm{~Hz}$ are used to evaluate the method performance to discriminate close components. The sinusoid with variable frequency emulates a startup transient reaching the steady state at $56.7 \mathrm{~Hz}$, which is closely located to a constant frequency component at $80 \mathrm{~Hz}$. Finally, Gaussian noise $\left(n_{G}\right)$ is added to evaluate the behavior of the treated method to low signal-to-noise ratio signals. The synthetic signal is quantized at a sampling frequency of $1.5 \mathrm{kHz}$, comprising 4096 samples for a total running time of $2.73 \mathrm{~s}$. Also the synthetic signal has a signal-to-noise ratio equal to $\mathrm{SNR}=-3.6 \mathrm{~dB}$ :

$$
\begin{gathered}
x(t)=\sin \left(\omega_{1} t\right)+\sin \left(\omega_{2} t\right)+\sin \left(\omega_{3} t\right)+\sin \left(\omega_{4} t\right) \\
+n_{G}, \quad \omega_{h}=2 \pi f_{h} \quad \text { for } h=1,2,3,4,
\end{gathered}
$$


where $x(t)$ is the synthetic signal, $f_{1}=80, f_{2}=670, f_{3}=700$, and

$$
f_{4}=\left\{\begin{array}{cl}
\frac{56.7}{2} t & 0 \leq t \leq 2 \\
56.7 & 2<t .
\end{array}\right.
$$

Figure 1 shows the results of the validation process for the synthetic signal in the time domain and the timefrequency decomposition obtained with the treated methods. In Figure 1(a) the time-domain synthetic signal is depicted. The true (theoretical) time-frequency decomposition is shown in Figure 1(b). The time-frequency decompositions of the treated methods are depicted in Figure 1(c) for the STFT, Figure 1(d) for the TFDG, Figure 1(e) for the TFMS, and Figure 1(f) for MUSIC.

As it can be seen from Figure 1(c), the behavior of the STFT is not a good method for time-frequency decomposition when the signal-to-noise ratio is low; it is also very difficult to distinguish the two close frequencies at 670 and $700 \mathrm{~Hz}$, whereas the variable-frequency sinusoid is barely visible and at the steady state it is indistinguishable from the $80 \mathrm{~Hz}$ spectral component. On the other hand, the other proposed methods are able to distinguish the spectral components from the background noise. The three methods clearly detect the time evolution of the variable-frequency sinusoid and the $80 \mathrm{~Hz}$ component is also clearly visible. Yet, the TFDG and MUSIC methods detect the close spectral components located at 670 and $700 \mathrm{~Hz}$, but the TFMS method is unable to give a clear result in this region, and MUSIC is able to show the three frequencies without any noise in its spectrum. Finally, it is concluded that MUSIC is the best time-frequency decomposition from the four tested methods where the obtained spectrum is less susceptible to low signalto-noise ratio.

\section{Experimental Setup}

The test bench used for testing the motors with different types of faults and the data acquisition system used to capture the signals is shown in Figure 2. Several squirrel-cage induction motors, model WEG 00136APE48T, of $1 \mathrm{hp}(745.7 \mathrm{~W})$ are used for testing the treated healthy and faulty conditions on the motor. The motors have two poles, 28 bars, they are fed with a voltage of $220 \mathrm{Vac}$ at $60 \mathrm{~Hz}$, and the applied load is a conventional alternator. The vibration signals are acquired using a microelectromechanical-systems-based triaxial accelerometer (model LIS3L02AS4) from STMicroelectronics. A 12-bit four-channel serial-output analog-to-digital converter (ADS7841) is used for data acquisition (DAS). This data acquisition system uses a sampling frequency $f_{0}$ of $1.5 \mathrm{kHz}$, and 4096 samples are obtained during the startup transient. Figures 2(b) and 2(c) present a frontal and lateral view of the induction motor, respectively, indicating the position of the accelerometer and the orientation of its axes.

5.1. Motor Faults. The UNB condition is present when the induction motor mechanical load is not uniformly distributed, taking the center of mass out of the motor shaft.
Figure 3 shows a pulley with an off-centered mass used for generating the UNB condition on the induction motor. The signature of UNB in a vibration signal normally has the form of increased amplitude along the rotor frequency, being located in this case at $56.7 \mathrm{~Hz}$.

To carry out the faulty bearing test, the bearing is artificially damaged by drilling a hole with $1.191 \mathrm{~mm}$ of diameter on its outer race using a tungsten drill bit. Figure 4 shows the artificially damaged bearing model 6203-2ZNR used in this experimentation. The vibration characteristicdefect frequency of the rolling element bearing outer race is calculated by using (2). The tested induction motor has a rotor frequency $f_{r}=56.7 \mathrm{~Hz}$, and a test bearing having eight balls of $6.5 \mathrm{~mm}$ diameter and a cage diameter of the bearing of $28 \mathrm{~mm}$ with contact angle $\theta=0$; thus, the ball-pass outer raceway frequency defect $\left(f_{\mathrm{BPOF}}\right)$ is found to be at $174.1 \mathrm{~Hz}$.

As aforementioned, the BRB-fault-specific frequencies depend on the speed oscillation with frequency $2 s f s$. The broken bar condition is produced artificially by drilling one hole with $7.938 \mathrm{~mm}$ of diameter without harming the rotor shaft. Figure 5 depicts the utilized rotor with one BRB. The motor is running at $3402 \mathrm{rpm}$ in a $60 \mathrm{~Hz}$ system. The harmonics, specific to the BRB fault, are obtained by first incorporating the actual motor speed data values into (4) to find the slip value $(s=0.055)$ which can be used in (3) to obtain the harmonic frequencies associated with the BRB.

5.2. Methodology. Figure 6 depicts a block diagram of the proposed methodology. First, the test bench is set with the induction motor at different conditions: healthy, one and two broken rotor bars, unbalanced pulley, and bearing fault in the outer race. Then, the data acquisition process is started to acquire the startup transient of the vibrations through the triaxial accelerometer. During the startup transient, 4096 samples are acquired at $1.5 \mathrm{kHz}$ for an acquisition time of $2.73 \mathrm{~s}$. After the acquisition process of the startup transient is completed, the acquired vibration signals are processed and analyzed. At this stage the TFDG, TFMS, and MUSIC timefrequency decomposition methodologies are applied and compared to the STFT. Finally, from the results of the timefrequency decomposition spectrograms a motor condition is determined. Also, a qualitative and quantitative evaluation of the distributions used to assess their performance is made, compared to the STFT.

\section{Results and Discussion}

This section provides the results obtained after analyzing the vibration signals with the time-frequency decomposition techniques, TFDG, TFMS, and MUSIC, including a comparison with the STFT. These vibration signals are captured from the startup transients of the motors under the five different conditions, that is, healthy, one broken rotor bar, two broken rotor bars, unbalance, and bearing defects. The best results are obtained from the vibration signal in the $z$ axis, $A_{z}$, and this is because vibrations in an induction motor are typically radial vibrations (vertical or $A_{z}$ axis) due to the radial forces acting on the stator and the rotor associated 


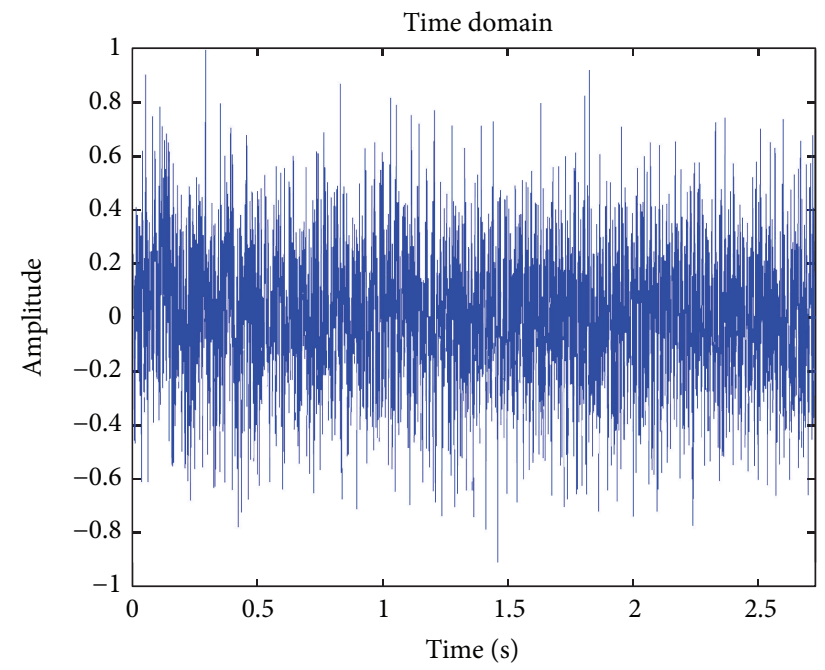

(a)

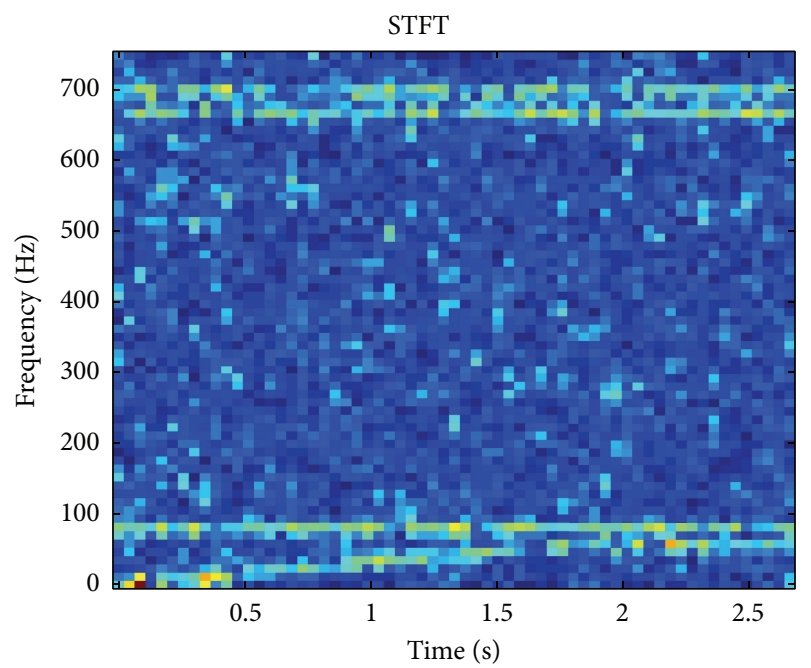

(c)

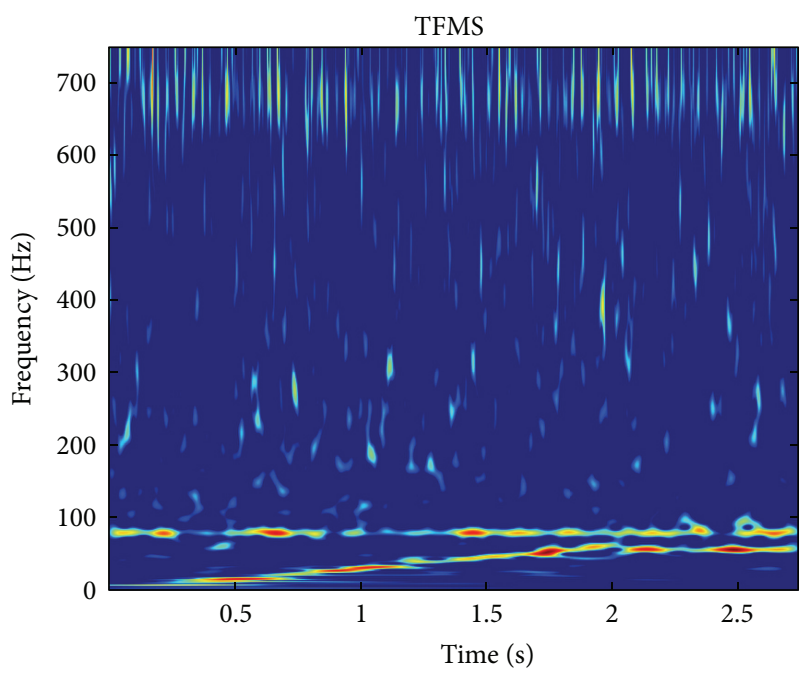

(e)

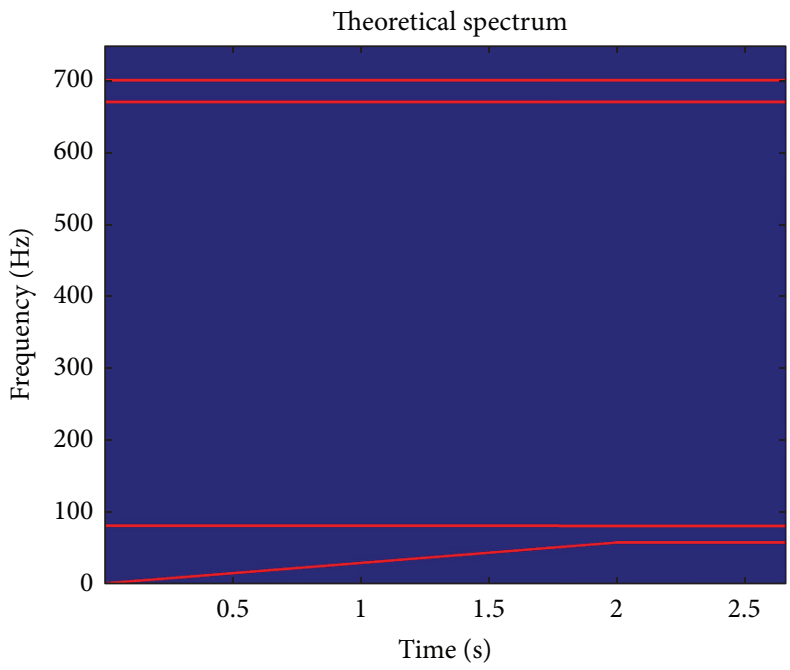

(b)

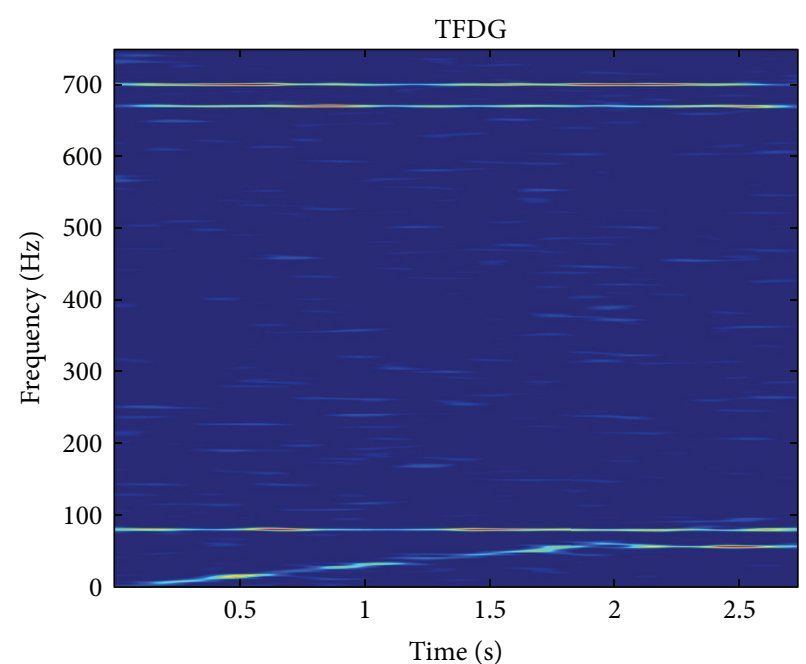

(d)

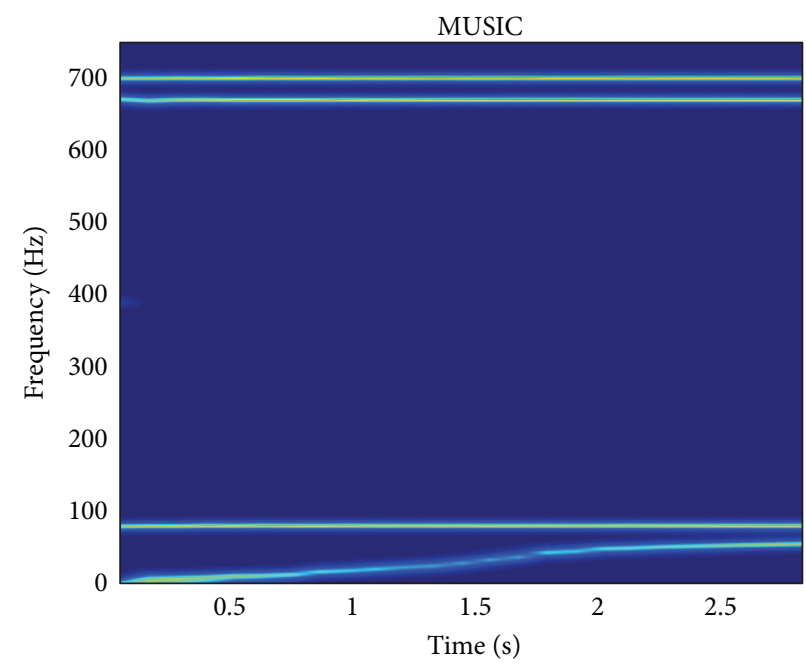

(f)

FIGURE 1: Validation of the proposed time-frequency decomposition methods. (a) Synthetic signal in the time domain. (b) Theoretical timefrequency decomposition of the synthetic signal. (c) STFT. (d) TFDG. (e) TFMS. (f) MUSIC. 


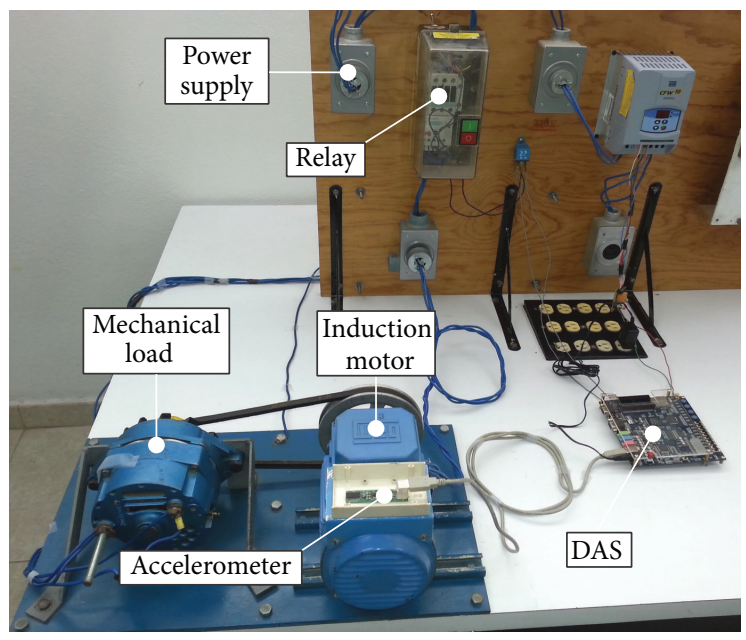

(a)

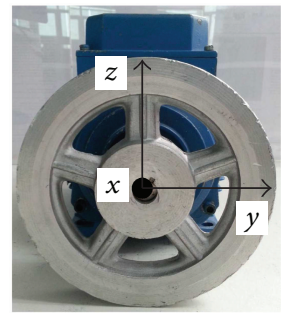

(b)

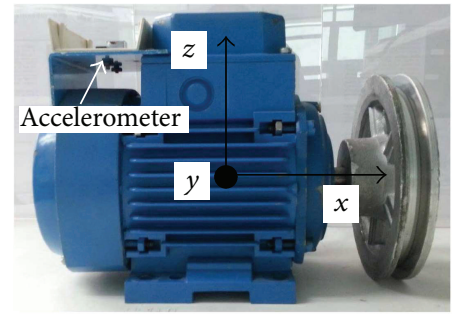

(c)

Figure 2: Test bench used for testing motors. (a) General view. (b) Frontal view of the motor showing the orientation of the accelerometer axes. (c) Lateral view of the motor showing the orientation of the accelerometer axes.

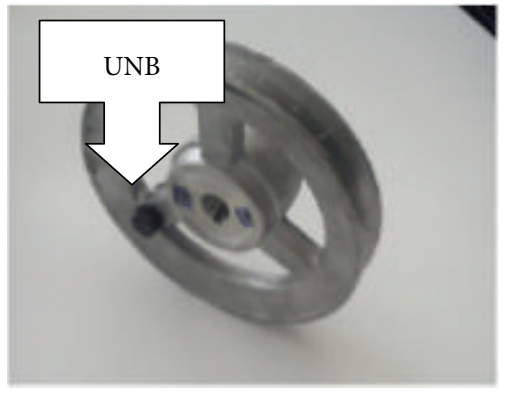

FIGURE 3: Unbalanced pulley.

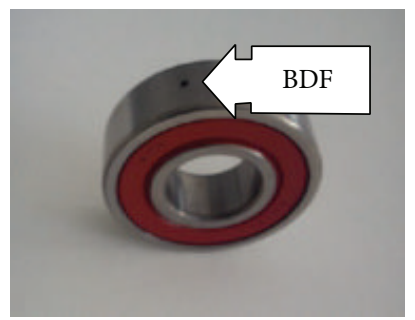

FIGURE 4: Outer race damaged bearing.

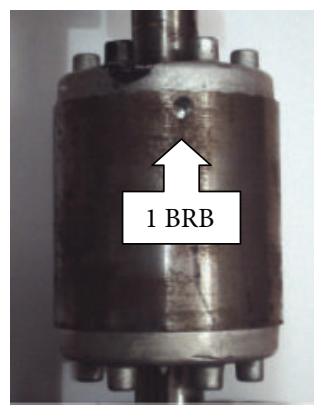

FIGURE 5: One broken rotor bar.

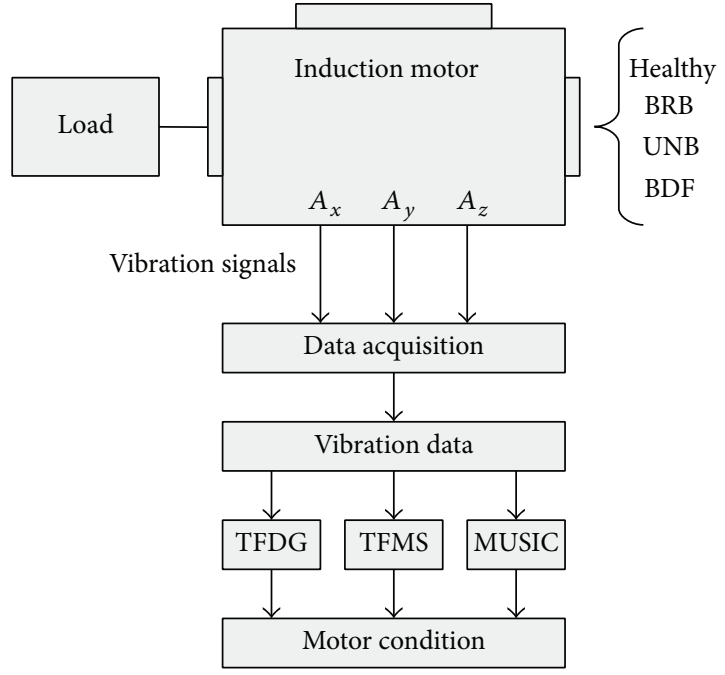

FIGURE 6: Block diagram of the proposed methodology.

with the magnetic fluxes entering or leaving the iron surfaces in the induction motor, and the presence of spectral flux components produced by the current density distributions, stator and rotor slotting, and also the magnetic saturation that introduces additional undesired components in the radial forces [7]. The results are provided in four cases of study and a qualitative analysis about the motor operation condition is given.

Case of Study: Healthy. Figure 7 presents the STFT, TFDG, TFMS, and MUSIC time-frequency decomposition of the $A_{z}$ signal for the healthy case. For this case of study, the frequency band between $400 \mathrm{~Hz}$ and $700 \mathrm{~Hz}$ has some barely perceptible variations associated with preexistent eccentricities in the motor, which are only perceptible after the 


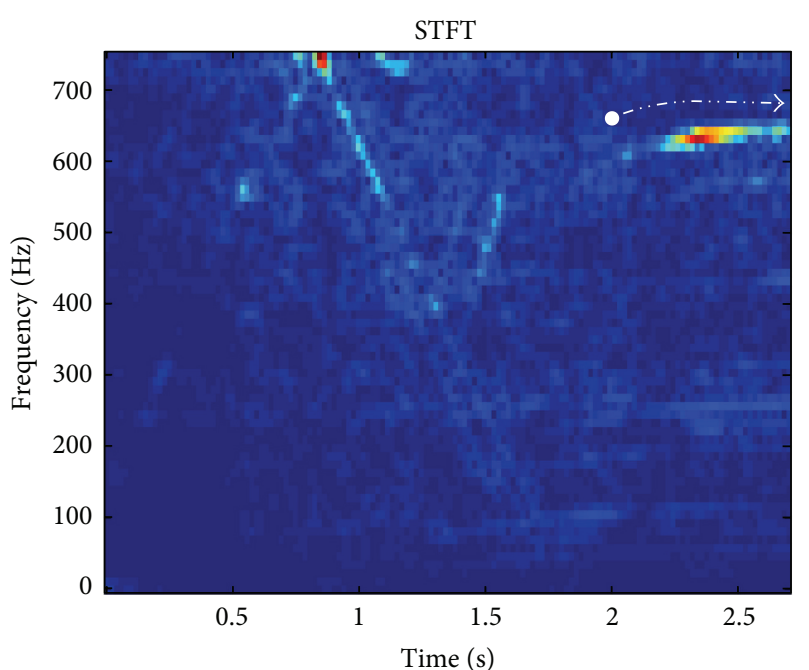

(a)

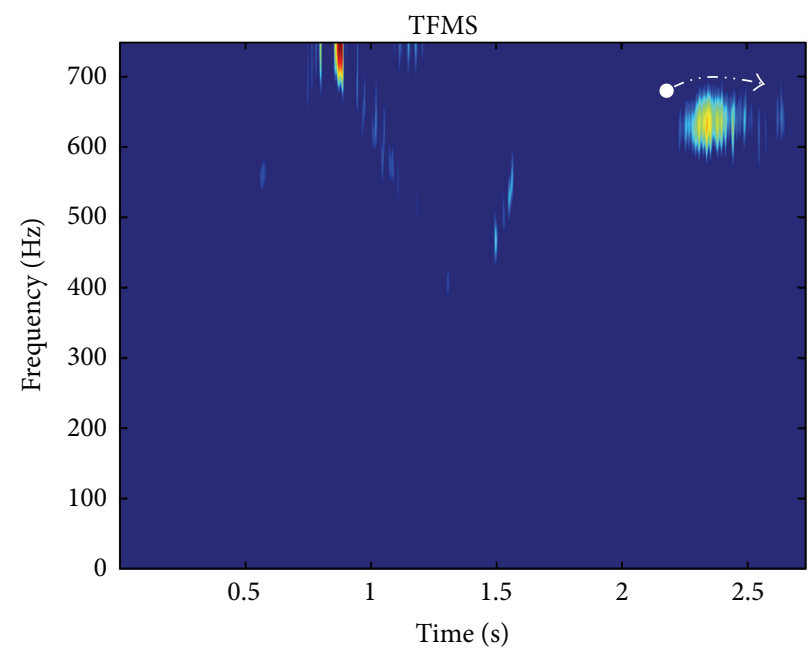

(c)

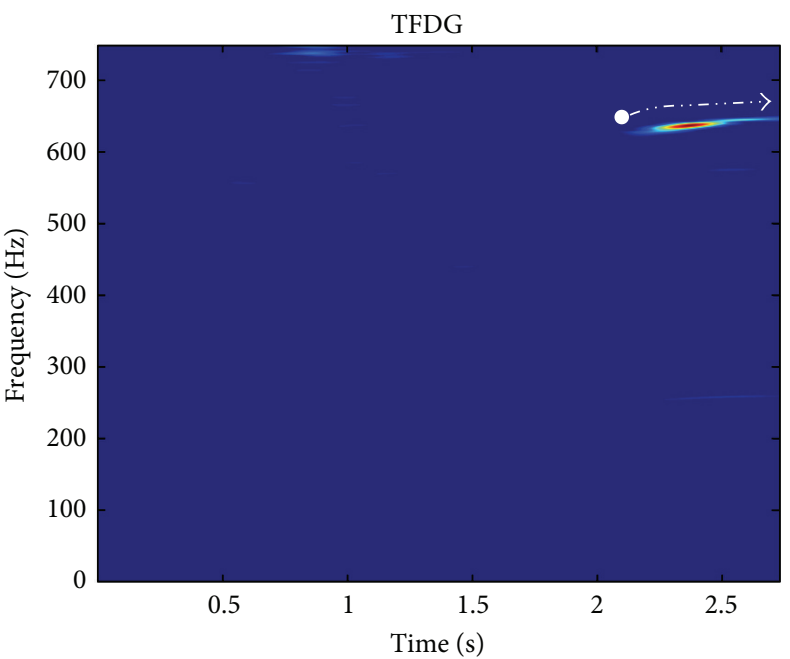

(b)

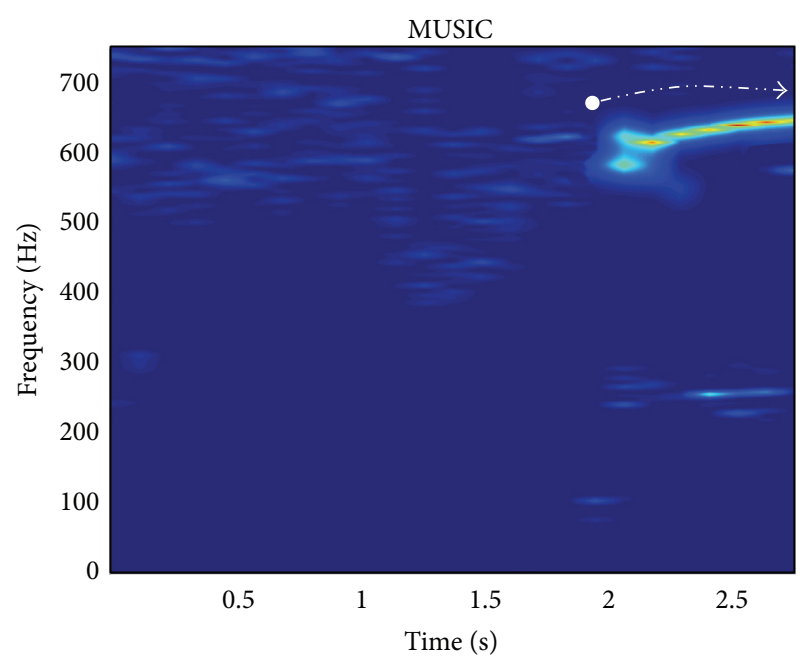

(d)

FIGURE 7: Time-frequency decomposition spectrograms for a healthy motor. (a) STFT. (b) TFDG. (c) TFMS. (d) MUSIC.

startup transient when the steady-state regime is reached. There are no other significant frequency components in the spectrograms for the healthy case of study, and these spectrograms become the reference for comparing the faulty conditions on the motor.

Case of Study: Broken Rotor Bars. As previously mentioned, the fault of broken rotor bars can be detected by observing the frequency evolution in the spectrogram. From (3), and the obtained spectrograms, it is observed for $k=11$ and $n=1$ that there is a harmonic $(617.1 \mathrm{~Hz})$ of the BRB frequency fault close to the $640 \mathrm{~Hz}$ frequency showed in the healthy case spectrograms. Figure 8(a) shows the STFT spectrogram, and there is a significant frequency bandwidth around $620-655 \mathrm{~Hz}$, but the harmonic $(617.1 \mathrm{~Hz})$ of the BRB frequency fault is not clearly detected. Figure 8(b) presents the TFDG spectrogram, and the significant frequency is around $640 \mathrm{~Hz}$, so the harmonic is not detected. Figure 8 (c) displays the TFMS spectrogram, and this is the worst method because the significant frequency bandwidth is located around $610-690 \mathrm{~Hz}$, so the BRB frequency fault is not detected. Figure 8(a) shows the MUSIC spectrogram where the harmonic $(617.1 \mathrm{~Hz})$ of the BRB frequency fault is clearly detected when the startup-regime is ending and the steady state starts (remarked in white).

Figure 9 shows the STFT, TFDG, TFMS, and MUSIC time-frequency decomposition spectrograms for the twobroken-rotor-bar case. For this case of study, the BRB frequency fault when $k=2$ and $n=4(87 \mathrm{~Hz})$ and the other harmonic $k=5$ and $n=3(263.7 \mathrm{~Hz})$ are present in most of the obtained spectrograms (remarked in white). Figure 9(a) shows the STFT spectrogram; however, the BRB frequency 


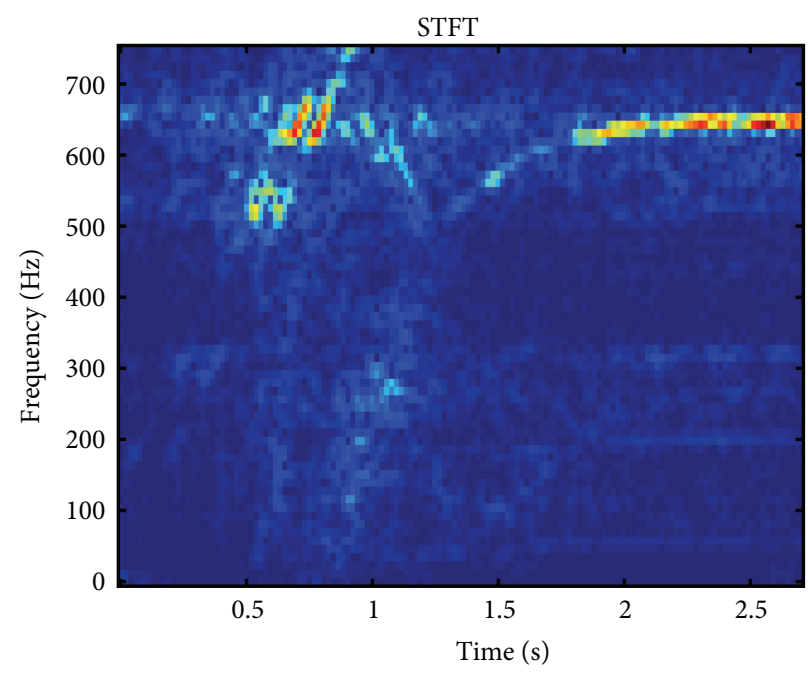

(a)

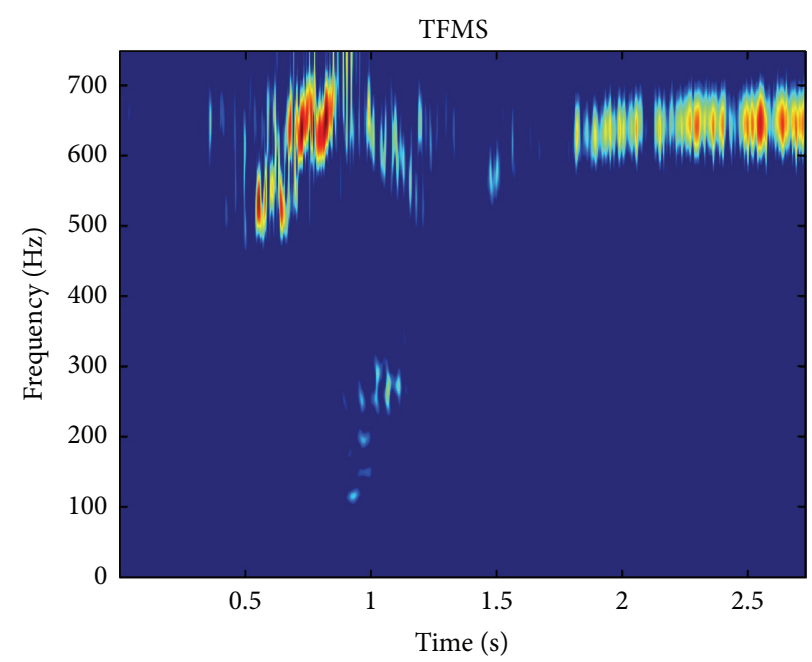

(c)

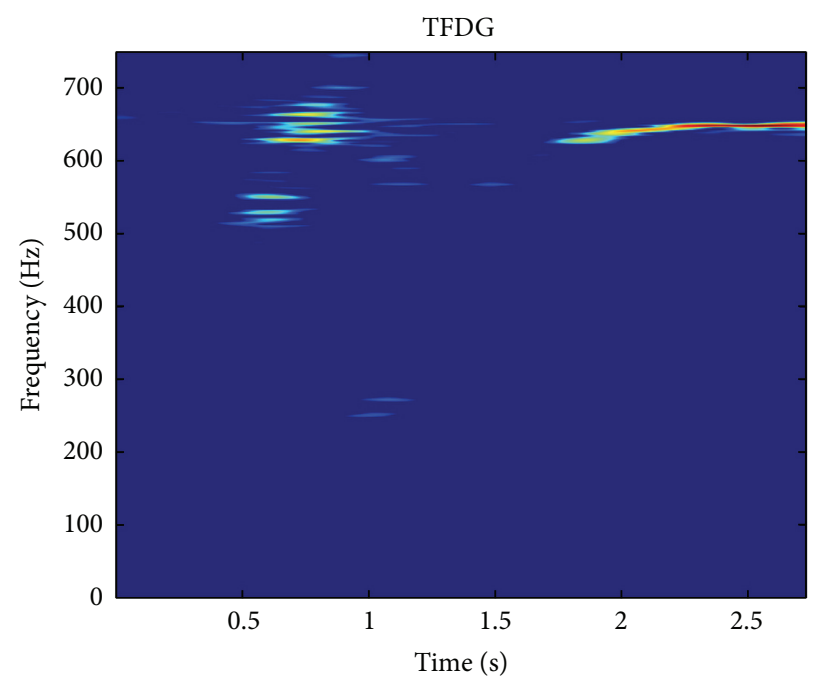

(b)

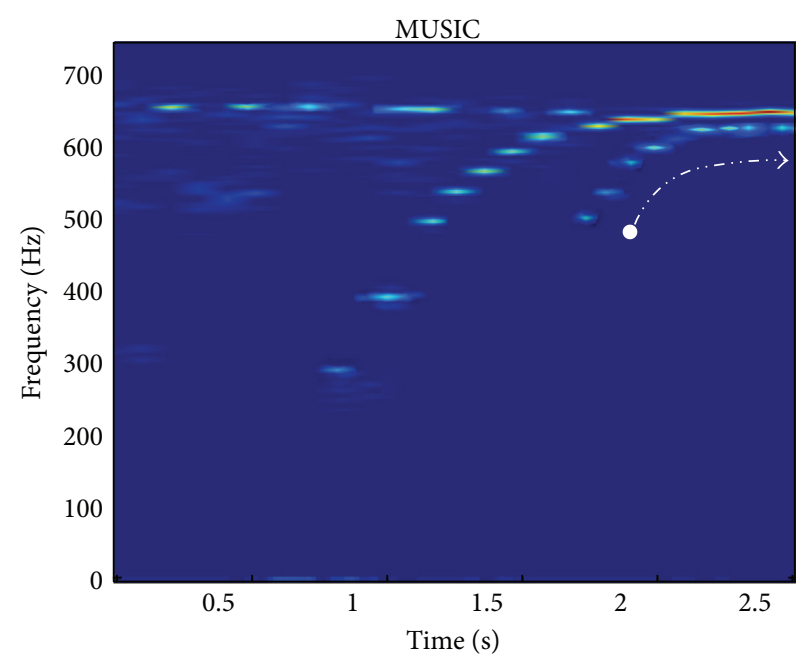

(d)

FIGURE 8: Time-frequency decomposition spectrograms for one broken rotor bar. (a) STFT. (b) TFDG. (c) TFMS. (d) MUSIC.

fault and the harmonics in $87 \mathrm{~Hz}$ and $263.7 \mathrm{~Hz}$ are not clearly observed as in the other methods. Figure 9(b) displays the TFDG spectrograms, but in this method, both frequencies are better observed with less noise interference, and these frequencies show better resolution as STFT. Figure 9(c) shows the TFMS spectrogram, where just the BRB frequency fault is slightly observed during the steady state start. Figure 9(d) presents the MUSIC spectrogram, and this method provides the best viewing for the studied case with the BRB frequency fault and its harmonics $(87 \mathrm{~Hz}$ and $263.7 \mathrm{~Hz})$ during the startup end and steady starts. But also the harmonic in $617.1 \mathrm{~Hz}$ is slightly detected during the beginning of the steady-state regime.

Case of Study: Unbalance. Figure 10 shows the STFT, TFDG, TFMS, and MUSIC analysis for the unbalanced case. In this case the motor speed in revolutions per minute corresponds to a frequency component located at $f_{r}=56.7 \mathrm{~Hz}$.

As seen from Figure 10, there is a frequency component around $56.7 \mathrm{~Hz}$ which is clearly defined. This frequency component is associated with the rotor speed and its increased value points towards the presence of unbalance in the operating condition. Notice that in the healthy case there are no significant frequency components at $56.7 \mathrm{~Hz}$ in the timefrequency spectrograms, demonstrating the presence of this fault. For all the analysis methods: STFT, TFDG, TFMS, and MUSIC, the associated frequency with this fault is clearly visible (remarked in white). This fault also contributes to the formation of peaks in the frequency band associated with the eccentricity of the motor, but what makes the identification possible is an increase in the amplitude of the spectral component that is associated with the rotation of the rotor, 


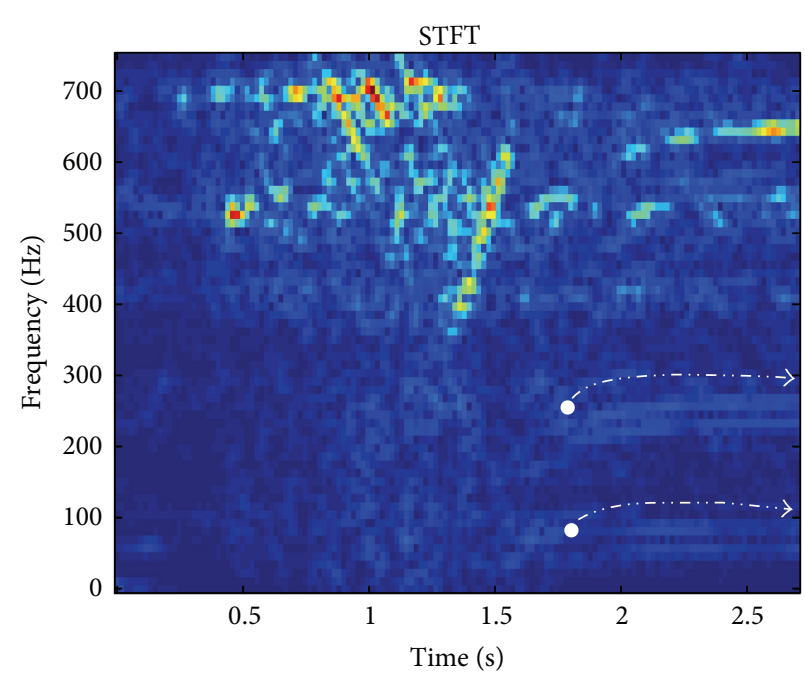

(a)

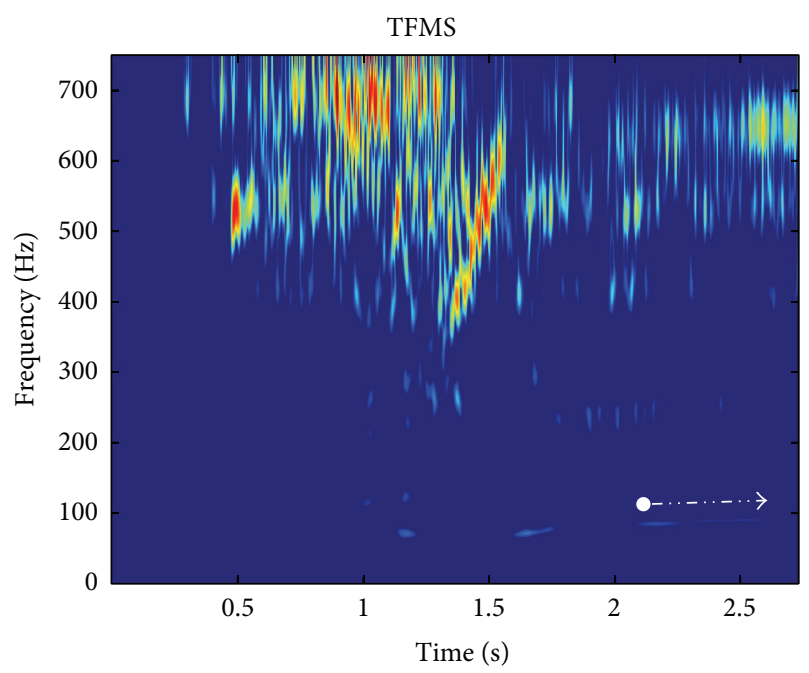

(c)

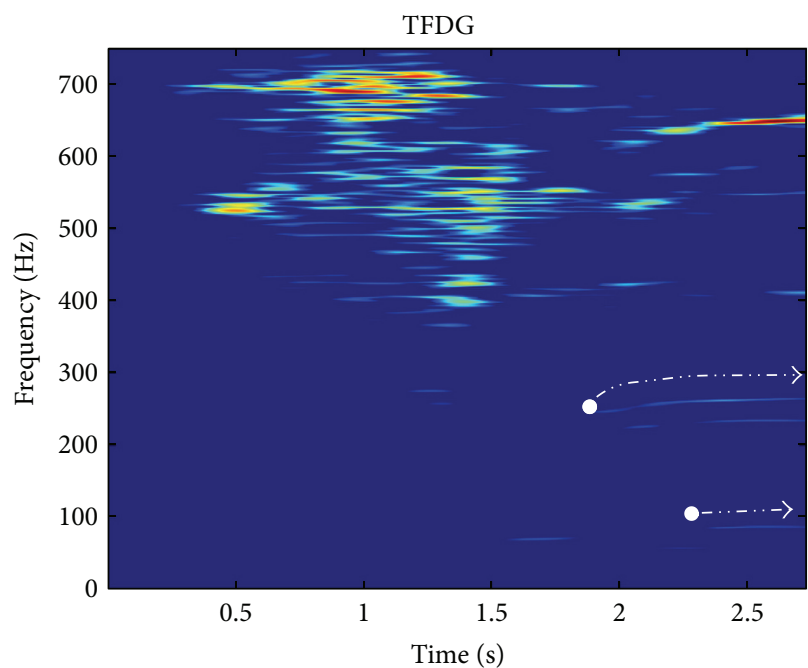

(b)

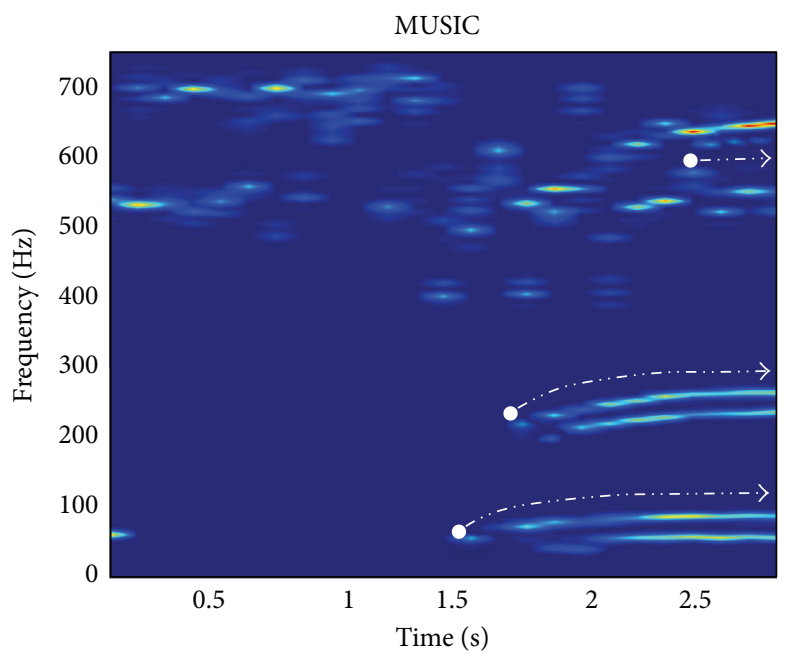

(d)

FIGURE 9: Time-frequency decomposition spectrograms for two broken rotor bars. (a) STFT. (b) TFDG. (c) TFMS. (d) MUSIC.

and MUSIC provides the best visualization of the fault-related frequency component.

Case of Study: Bearing Defects. Figure 11 depicts the STFT, TFDG, TFMS, and MUSIC time-frequency decomposition spectrograms for the bearing defects case. As previously mentioned, a defect on the outer race causes an impulse each time a rolling element contacts the defect. Thus, the related frequency to this fault is associated with the rotation of the shaft, and the fault-related frequency of the ballpass outer raceway $\left(f_{\mathrm{BPOF}}\right)$ is located at $174.1 \mathrm{~Hz}$. MUSIC is the only method able to detect this frequency in the 3rd harmonic $(522 \mathrm{~Hz})$ at the ending of the startup transient and the beginning of the steady-state regime (remarked in white).

In order to quantitatively evaluate the efficiency of the different spectral estimation methods, a detectability comparison in decibels is presented. The detectability is calculated as the average in the amplitude ratio between the peak amplitude for the healthy and faulty conditions of the spectral frequencies that are present in the region of evolution. The comparative study is summarized in Table 1 and the study assesses the effectiveness of the MUSIC spectral estimation method in the detection of the broken rotor bar, mechanical unbalance, and bearing faults over the other methods.

Table 1 shows that MUSIC provides a better fault detectability for the three studied faults in an induction motor during the startup transient regime because it presents greater detectability for all conditions.

\section{Conclusions}

The feasibility of detecting faults in induction motors using the time-frequency spectral analysis techniques proposed in this paper has been shown, applied to vibration signals. The methodology proposed in this paper is applicable when it does not have current signals and only has vibration 


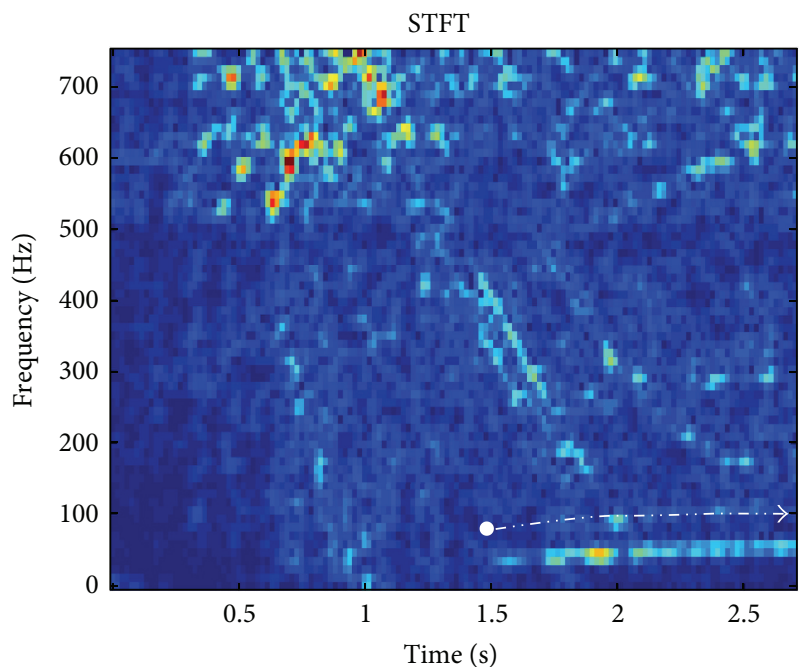

(a)

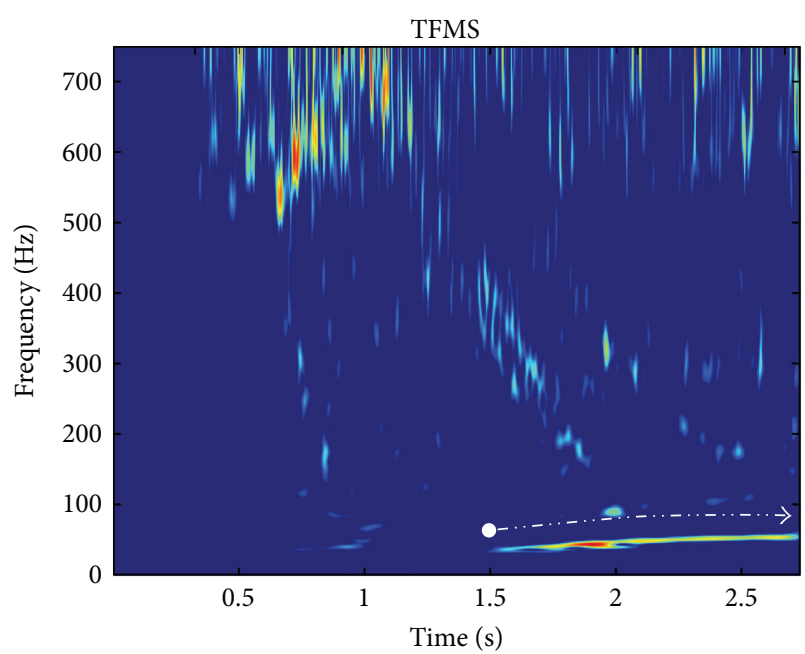

(c)

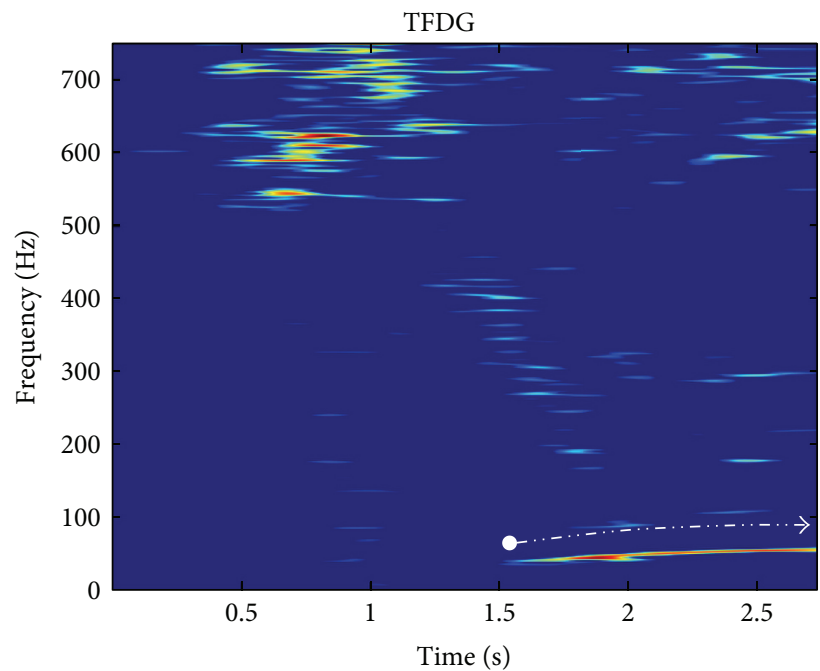

(b)

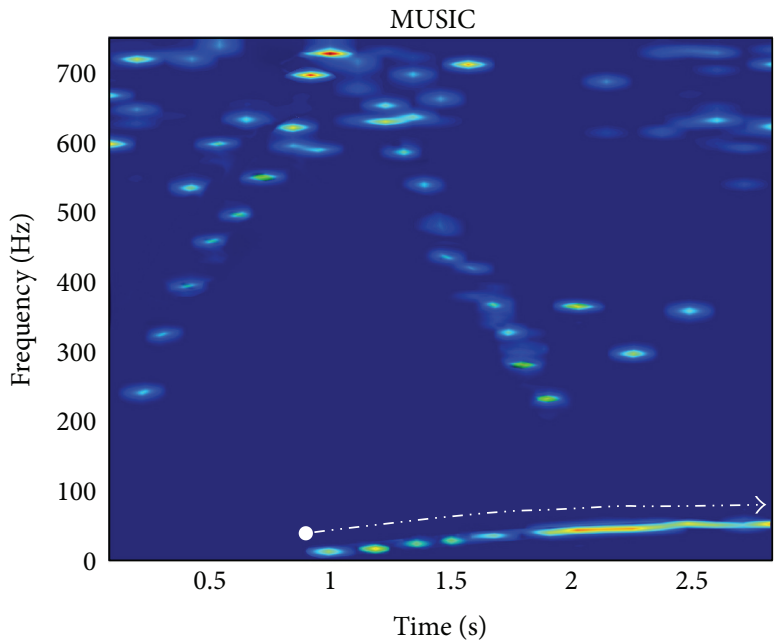

(d)

FIGURE 10: Time-frequency decomposition spectrograms for an unbalance case. (a) STFT. (b) TFDG. (c) TFMS. (d) MUSIC.

TABLE 1: Detectability in decibels of the comparative study of different techniques for identifying faults in an induction motor.

\begin{tabular}{lcccc}
\hline Condition & STFT & TFDG & TFMS & MUSIC \\
\hline Healthy & 10 & 7 & 11 & 12 \\
Broken rotor bar & 12 & 9 & 13 & $\mathbf{2 1}$ \\
Mechanical unbalance & 15 & 10 & 6 & $\mathbf{2 8}$ \\
Bearing fault & 16 & 12 & 21 & $\mathbf{3 2}$ \\
\hline
\end{tabular}

signals. This methodology also has applications in motors that are not fed directly to the supply line; in such cases the analysis of current signals is not recommended due to poor current signal quality. Similarly with the use of this methodology can be detected faults as MCSA performed on induction motor current monitoring. The time-frequency decomposition method that provides better results is the MUSIC, which has higher frequency resolution and is able to detect the frequencies and their harmonics associated with the treated faults in highly noisy vibration signal. For further development, a classification system for the automatic detection of faults can be included. Also, the analysis applied to the fusion of data from the acceleration and current sensors could produce an improved methodology for fault detection in induction motors.

\section{Conflict of Interests}

The authors declare that there is no conflict of interests regarding the publication of this paper.

\section{Acknowledgments}

This research was partially supported by CONACYT Scholarship 237491, Universidad de Guanajuato SEP PIFI 2014 grant, and University of Valladolid, Project 061/130251. 


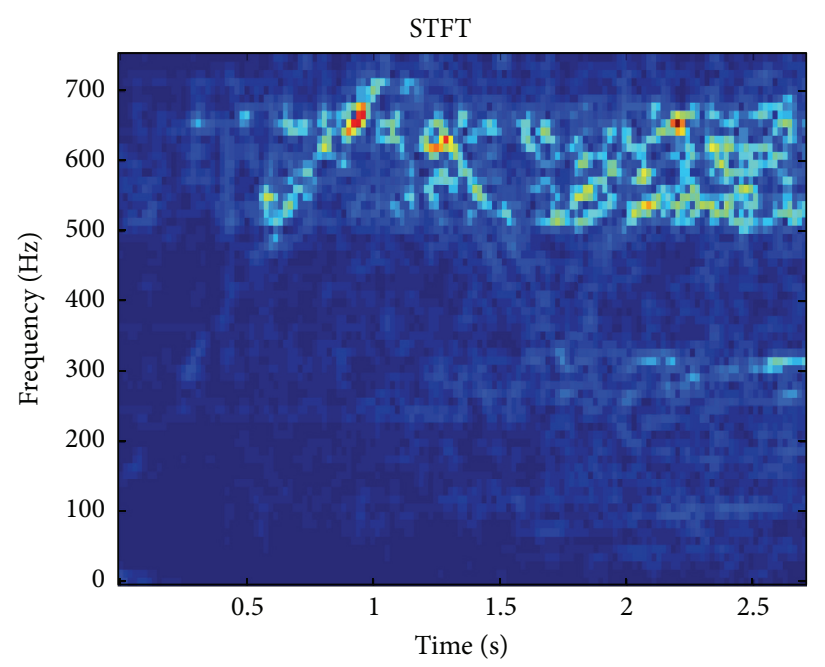

(a)

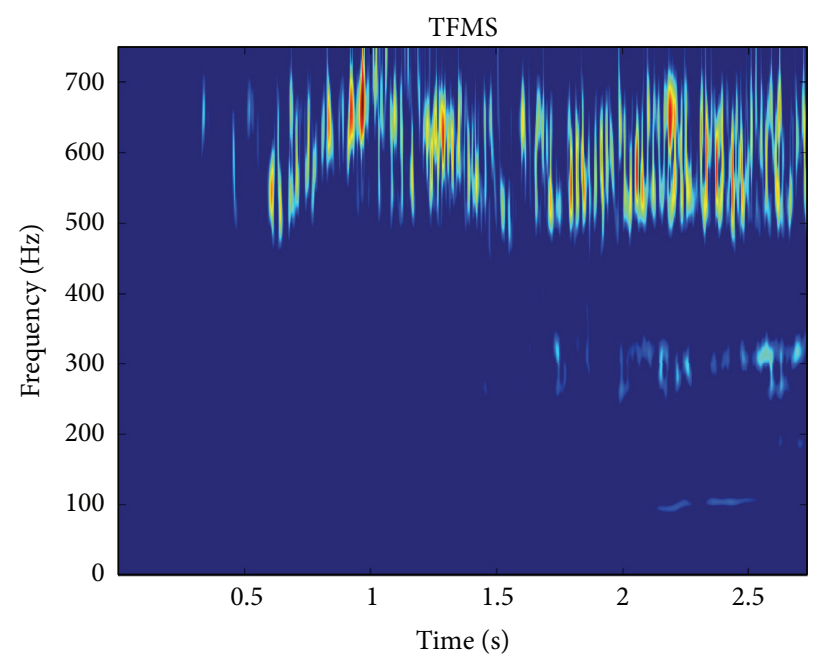

(c)

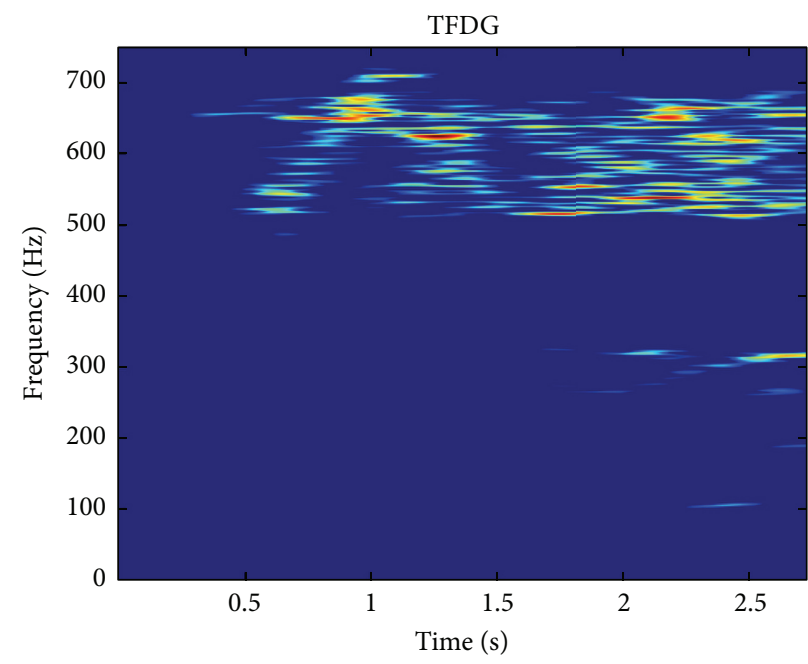

(b)

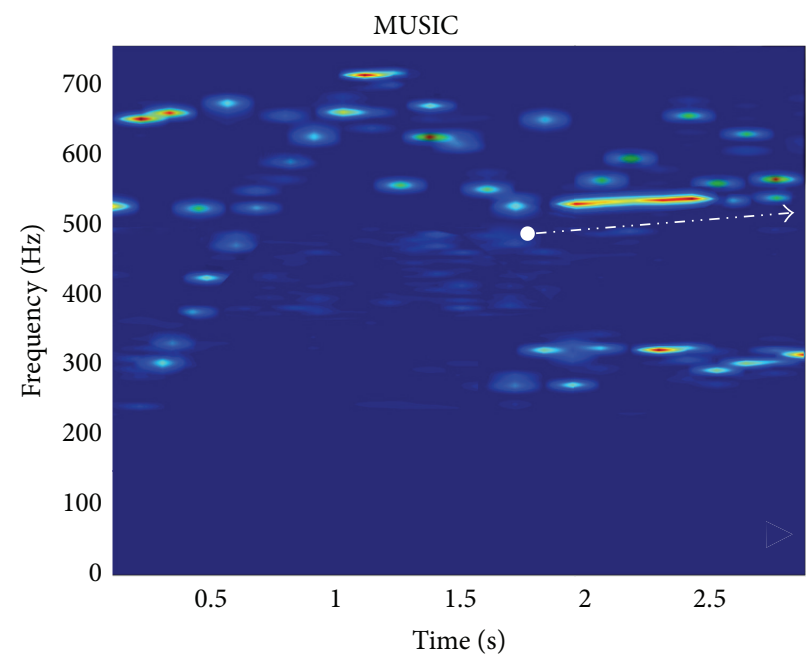

(d)

FIGURE 11: Time-frequency decomposition spectrograms for the bearing defect case. (a) STFT. (b) TFDG. (c) TFMS. (d) MUSIC.

\section{References}

[1] US Energy Information Administration, Electricity Use by Machine Drives Varies Significantly by Manufacturing Industry, US Energy Information Administration, 2013, http://www.eia .gov/todayinenergy/detail.cfm?id=13431.

[2] M. E. H. Benbouzid, "A review of induction motors signature analysis as a medium for faults detection," IEEE Transactions on Industrial Electronics, vol. 47, no. 5, pp. 984-993, 2000.

[3] W. T. Thomson and M. Fenger, "Current signature analysis to detect induction motor faults," IEEE Industry Applications Magazine, vol. 7, no. 4, pp. 26-34, 2001.

[4] V. Ghorbanian and J. Faiz, "A survey on time and frequency characteristics of induction motors with broken rotor bars in line-start and inverter-fed modes," Mechanical Systems and Signal Processing, vol. 54-55, pp. 427-456, 2015.

[5] A. Garcia-Perez, R. D. J. Romero-Troncoso, E. Cabal-Yepez, and R. A. Osornio-Rios, "The application of high-resolution spectral analysis for identifying multiple combined faults in induction motors," IEEE Transactions on Industrial Electronics, vol. 58, no. 5, pp. 2002-2010, 2011.

[6] S. Bindu and V. V. Thomas, "Diagnoses of internal faults of three phase squirrel cage induction motor-a review," in Proceedings of the International Conference on Advances in Energy Conversion Technologies, pp. 48-54, Manipal, India, January 2014.

[7] R. Miceli, Y. Gritli, A. di Tommaso, F. Filippetti, and C. Rossi, "Vibration signature analysis for monitoring rotor broken bar in double squirrel cage induction motors based on wavelet analysis," COMPEL, vol. 33, no. 5, pp. 1625-1641, 2014.

[8] P. C. M. L. Filho, J. N. Brito, V. A. D. Silva, and R. Pederiva, "Detection of electrical faults in induction motors using vibration analysis," Journal of Quality in Maintenance Engineering, vol. 19, no. 4, pp. 364-380, 2013.

[9] A. Gandhi, T. Corrigan, and L. Parsa, "Recent advances in modeling and online detection of stator interturn faults in electrical motors," IEEE Transactions on Industrial Electronics, vol. 58, no. 5, pp. 1564-1575, 2011. 
[10] H. Su, K. T. Chong, and R. Ravi Kumar, "Vibration signal analysis for electrical fault detection of induction machine using neural networks," Neural Computing and Applications, vol. 20, no. 2, pp. 183-194, 2011.

[11] S. Nandi, T. C. Ilamparithi, S. B. Lee, and D. Hyun, "Detection of eccentricity faults in induction machines based on nameplate parameters," IEEE Transactions on Industrial Electronics, vol. 58, no. 5, pp. 1673-1683, 2011.

[12] E. Cabal-Yepez, A. G. Garcia-Ramirez, R. J. Romero-Troncoso, A. Garcia-Perez, and R. A. Osornio-Rios, "Reconfigurable monitoring system for time-frequency analysis on industrial equipment through STFT and DWT,' IEEE Transactions on Industrial Informatics, vol. 9, no. 2, pp. 760-771, 2013.

[13] P. S. Panigrahy, P. Konar, and P. Chattopadhyay, "Broken bar fault detection using fused DWT-FFT in FPGA platform," in Proceedings of the International Conference on Power, Control and Embedded Systems (ICPCES '14), pp. 1-6, Allahabad, India, December 2014.

[14] I. S. Lee, "Fault diagnosis of induction motors using discrete wavelet transform and artificial neural network," in HCI International 2011-Posters' Extended Abstracts, pp. 510-514, Springer, Berlin, Germany, 2011.

[15] S. K. Ahamed, S. Karmakar, M. Mitra, and S. Sengupta, "Diagnosis of induction motor faults due to broken rotor bar and rotor mass unbalance through discrete wavelet transform of starting current at no-load," Journal of Electrical Systems, vol. 6, no. 3, pp. 442-456, 2010.

[16] A. Saghafinia, S. Kahourzade, A. Mahmoudi, W. P. Hew, and M. N. Uddin, "On line trained fuzzy logic and adaptive continuous wavelet transform based high precision fault detection of IM with broken rotor bars," in Proceedings of the IEEE Industry Applications Society Annual Meeting (IAS '12), pp. 1-8, Las Vegas, Nev, USA, October 2012.

[17] A. Saghafinia, S. Kahourzade, A. Mahmoudi, W. P. Hew, and M. Nasir Uddin, "Broken rotor bar fault detection of 3-phase induction motor using online adaptive continuous wavelet transform and fuzzy logic," International Review of Electrical Engineering, vol. 7, no. 3, pp. 4383-4394, 2012.

[18] S. Das, C. Koley, P. Purkait, and S. Chakravorti, "Wavelet aided SVM classifier for stator inter-turn fault monitoring in induction motors," in Proceedings of the IEEE Power and Energy Society General Meeting, pp. 1-6, Minneapolis, Minn, USA, July 2010.

[19] A. Pilloni, A. Pisano, M. Riera-Guasp, R. Puche-Panadero, and M. Pineda-Sanchez, "Fault detection in induction motors," in AC Electric Motors Control: Advanced Design Techniques and Applications, F. Giri, Ed., pp. 275-309, John Wiley \& Sons, Oxford, UK, 2013.

[20] J. A. Antonino-Daviu, M. Riera-Guasp, M. Pineda-Sanchez, and R. B. Pérez, "A critical comparison between DWT and Hilbert-Huang-based methods for the diagnosis of rotor bar failures in induction machines," IEEE Transactions on Industry Applications, vol. 45, no. 5, pp. 1794-1803, 2009.

[21] Z. K. Peng, P. W. Tse, and F. L. Chu, "A comparison study of improved Hilbert-Huang transform and wavelet transform: application to fault diagnosis for rolling bearing," Mechanical Systems and Signal Processing, vol. 19, no. 5, pp. 974-988, 2005.

[22] V. Climente-Alarcon, J. A. Antonino-Daviu, M. Riera-Guasp, and M. Vlcek, "Induction motor diagnosis by advanced notch FIR filters and the wigner-ville distribution," IEEE Transactions on Industrial Electronics, vol. 61, no. 8, pp. 4217-4227, 2014.
[23] S. S. Refaat, H. Abu-Rub, M. S. Saad, E. M. Aboul-Zahab, and A. Iqbal, "ANN-based for detection, diagnosis the bearing fault for three phase induction motors using current signal," in Proceedings of the IEEE International Conference on Industrial Technology (ICIT '13), pp. 253-258, Cape Town, South Africa, February 2013.

[24] V. Climente-Alarcon, J. A. Antonino-Daviu, M. Riera-Guasp, R. Puche-Panadero, and L. Escobar, "Application of the WignerVille distribution for the detection of rotor asymmetries and eccentricity through high-order harmonics," Electric Power Systems Research, vol. 91, pp. 28-36, 2012.

[25] V. Climente-Alarcon, J. A. Antonino-Daviu, M. Riera-Guasp et al., "Transient tracking of low and high-order eccentricityrelated components in induction motors via TFD tools," Mechanical Systems and Signal Processing, vol. 25, no. 2, pp. 667679, 2011.

[26] V. Climente-Alarcón, J. A. Antonino-Daviu, R. Riera-Guasp et al., "Diagnosis of stator short-circuits through Wigner-Ville transient-based analysis," in Proceedings of the 35th Annual Conference of the IEEE Industrial Electronics Society (IECON '09), pp. 1097-1102, Porto, Portugal, November 2009.

[27] M. Blödt, D. Bonacci, J. Regnier, M. Chabert, and J. Faucher, "On-line monitoring of mechanical faults in variable-speed induction motor drives using the Wigner distribution," IEEE Transactions on Industrial Electronics, vol. 55, no. 2, pp. 522-533, 2008.

[28] S. Rajagopalan, J. M. Aller, J. A. Restrepo, T. G. Habetler, and R. G. Harley, "Detection of rotor faults in brushless DC motors operating under nonstationary conditions," IEEE Transactions on Industry Applications, vol. 42, no. 6, pp. 1464-1477, 2006.

[29] P. Zhang, Y. Du, T. G. Habetler, and B. Lu, "A survey of condition monitoring and protection methods for medium-voltage induction motors," IEEE Transactions on Industry Applications, vol. 47, no. 1, pp. 34-46, 2011.

[30] A. Garcia-Perez, R. J. Romero-Troncoso, E. Cabal-Yepez, R. A. Osornio-Rios, and J. A. Lucio-Martinez, "Application of highresolution spectral analysis for identifying faults in induction motors by means of sound," Journal of Vibration and Control, vol. 18, no. 11, pp. 1585-1594, 2012.

[31] C. Rodriguez-Donate, R. J. Romero-Troncoso, E. Cabal-Yepez, A. Garcia-Perez, and R. A. Osornio-Rios, "Wavelet-based general methodology for multiple fault detection on induction motors at the startup vibration transient," Journal of Vibration and Control, vol. 17, no. 9, pp. 1299-1309, 2011.

[32] A. Garcia-Perez, R. J. Romero-Troncoso, E. Cabal-Yepez, R. A. Osornio-Rios, J. D. J. Rangel-Magdaleno, and H. Miranda, "Startup current analysis of incipient broken rotor bar in induction motors using high-resolution spectral analysis," in Proceedings of the IEEE International Symposium on Diagnostics for Electric Machines, Power Electronics \& Drives (SDEMPED '11), pp. 657-663, Bologna, Italy, September 2011.

[33] A. Bellini, C. Concari, G. Franceschini, C. Tassoni, and A. Toscani, "Vibrations, currents and stray flux signals to asses induction motors rotor conditions," in Proceedings of the 32nd Annual Conference on IEEE Industrial Electronics (IECON '06), pp. 4963-4968, IEEE, Paris, France, November 2006.

[34] V. Climente-Alarcon, J. A. Antonino-Daviu, F. Vedreño-Santos, and R. Puche-Panadero, "Vibration transient detection of broken rotor bars by PSH sidebands," IEEE Transactions on Industry Applications, vol. 49, no. 6, pp. 2576-2582, 2013.

[35] W. R. Finley, M. M. Hodowanec, and W. G. Holter, "An analytical approach to solving motor vibration problems," IEEE 
Transactions on Industry Applications, vol. 36, no. 5, pp. 14671480, 2000.

[36] M. Salah, K. Bacha, and A. Chaari, "Comparative investigation of diagnosis media for induction machine mechanical unbalance fault," ISA Transactions, vol. 52, no. 6, pp. 888-899, 2013.

[37] H. Bloch, Machinery Failure Analysis and Troubleshooting, Gulf Publishing, Houston, Tex, USA, 3rd edition, 1999.

[38] P. D. McFadden and J. D. Smith, "The vibration produced by multiple point defects in a rolling element bearing," Journal of Sound and Vibration, vol. 98, no. 2, pp. 263-273, 1985.

[39] Z. Kiral and H. Karagülle, "Simulation and analysis of vibration signals generated by rolling element bearing with defects," Tribology International, vol. 36, no. 9, pp. 667-678, 2003.

[40] A. Sadoughi, M. Ebrahimi, and E. Rezaei, "A new approach for induction motor broken bar diagnosis by using vibration spectrum," in Proceedings of the SICE-ICASE International Joint Conference, pp. 4715-4720, Busan, The Republic of Korea, October 2006.

[41] S.-H. Cho, G. Jang, and S.-H. Kwon, "Time-frequency analysis of power-quality disturbances via the Gabor-Wigner transform," IEEE Transactions on Power Delivery, vol. 25, no. 1, pp. 494-499, 2010.

[42] P. L. Søndergaard, "Efficient algorithms for the discrete Gabor transform with a long FIR window," Journal of Fourier Analysis and Applications, vol. 18, no. 3, pp. 456-470, 2012.

[43] M. J. Bastiaans and M. C. W. Geilen, "On the discrete Gabor transform and the discrete Zak transform," Signal Processing, vol. 49, no. 3, pp. 151-166, 1996.

[44] F. Auger, P. Flandrin, P. Gonçalvès, and O. Lemoine, TimeFrequency Toolbox For Use with MATLAB, CNRS, Paris, France; Rice University, Houston, Tex, USA, 1996.

[45] S. Mallat, A Wavelet Tour of Signal Processing: The Sparse Way, Academic Press, 2009. 

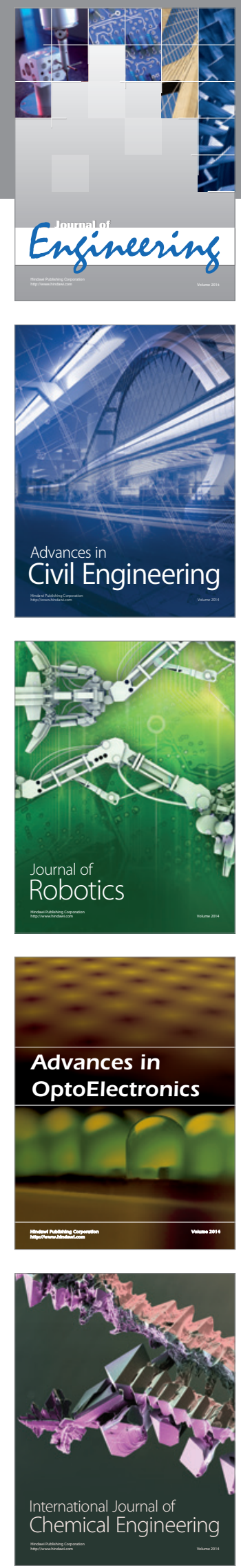

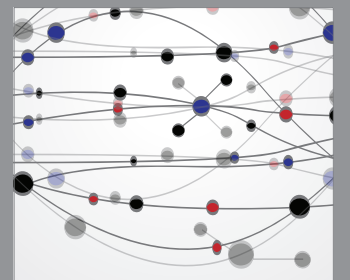

The Scientific World Journal
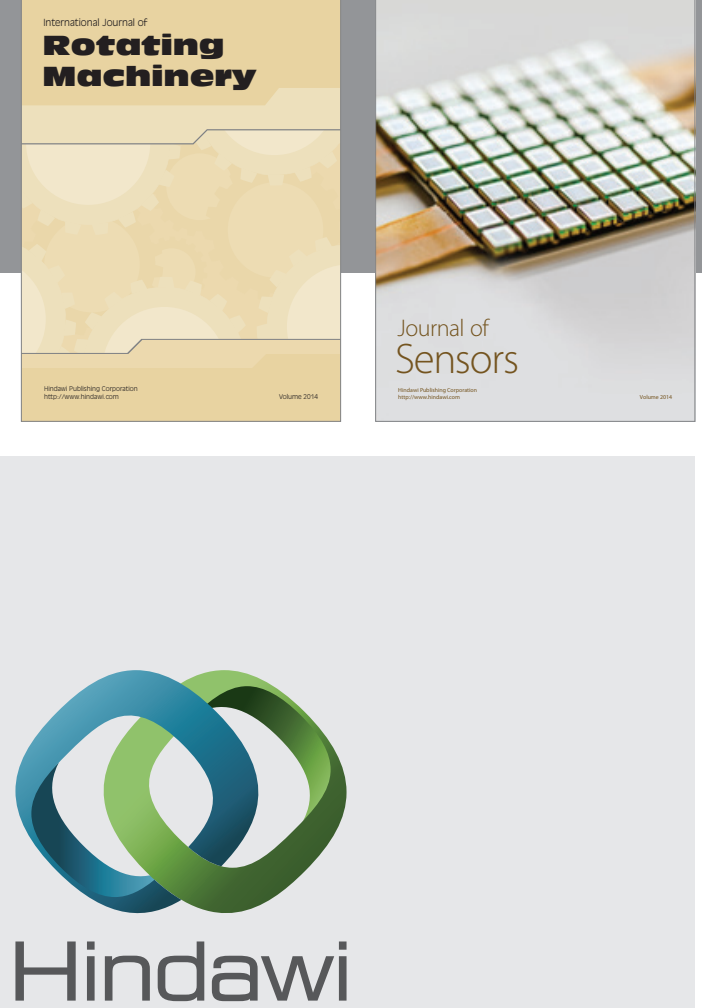

Submit your manuscripts at http://www.hindawi.com
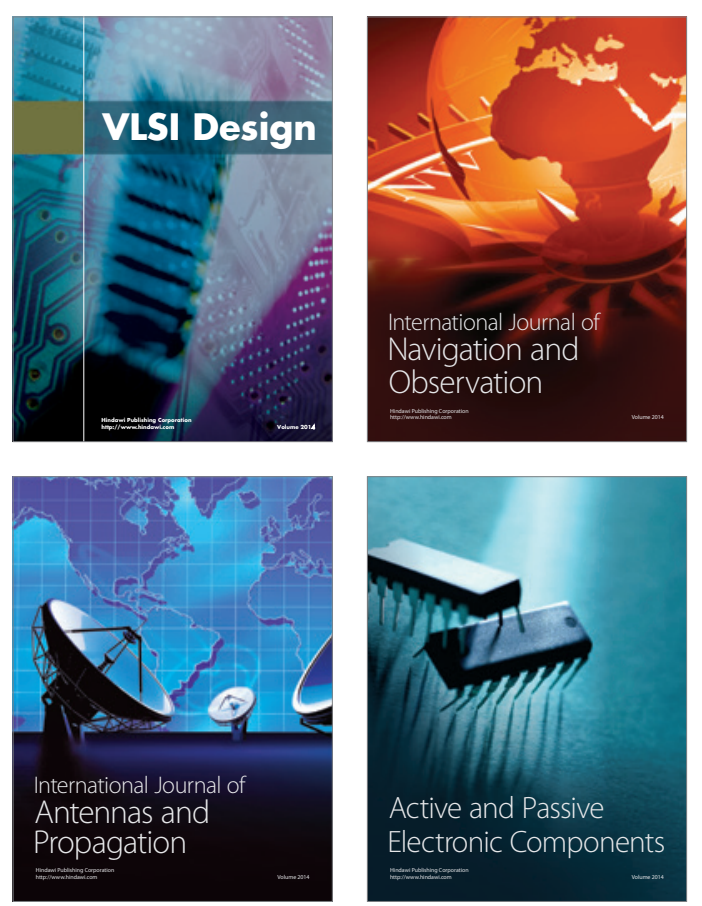
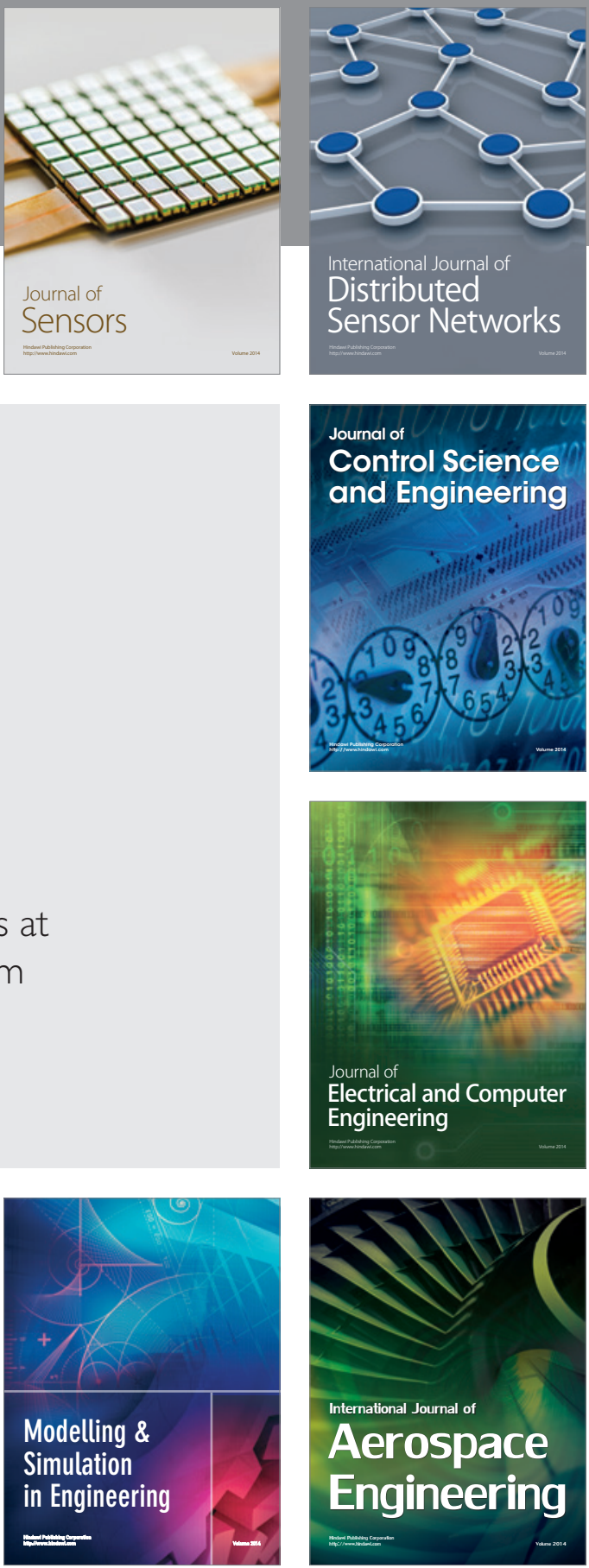

Journal of

Control Science

and Engineering
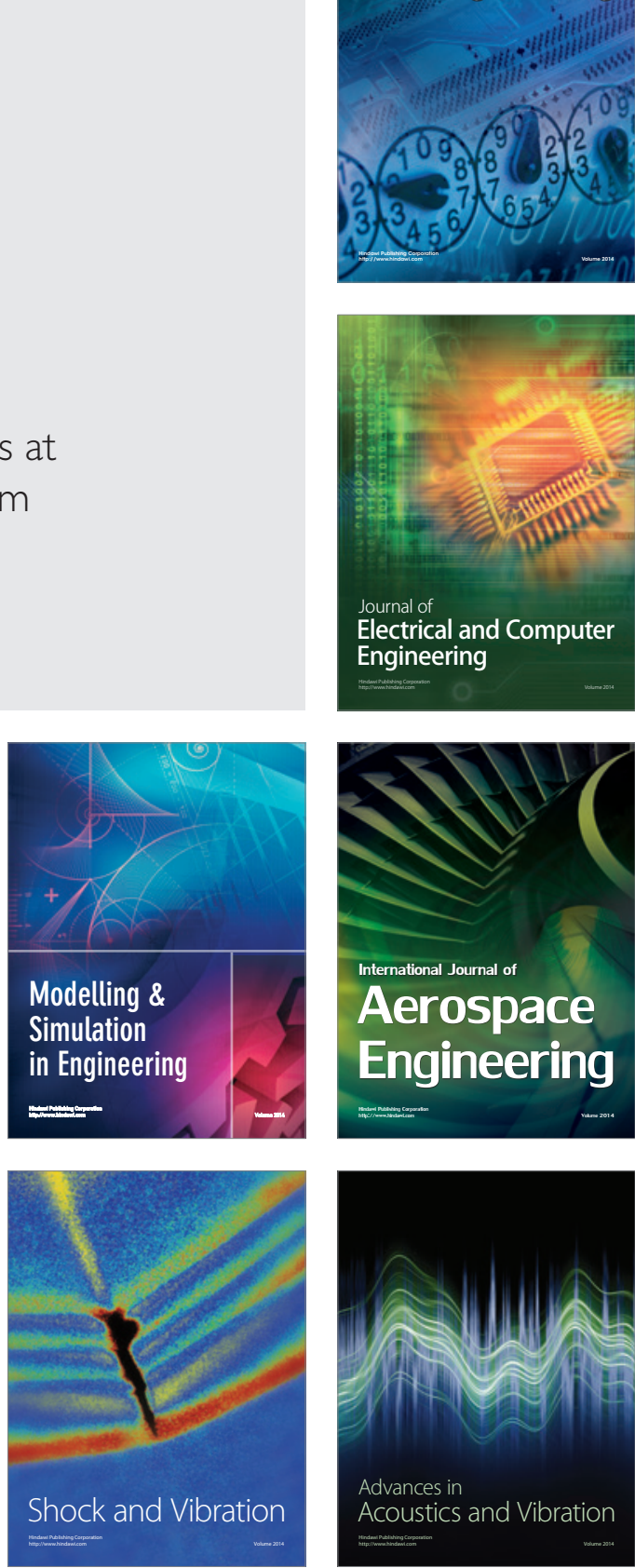